\title{
Tailor-made risk governance for induced seismicity of geothermal energy projects: An application to Switzerland
}

Author: Evelina Trutnevyte ${ }^{1,3}$, Stefan Wiemer ${ }^{2,3}$

\begin{abstract}
Fully open or partly open geothermal systems can induce potentially damaging seismicity. How this seismicity should be addressed depends on the geothermal system, its operational characteristics, the geological context, exposed buildings, existing infrastructure and populations, and social concern. This paper proposes an initial screening tool, called Geothermal Risk of Induced seismicity Diagnosis (GRID), for estimating to what extent induced seismicity is of concern for a specific project. A framework for tailor-made risk governance measures is then recommended, including hazard and risk assessment, social site characterization, seismic monitoring, insurance, structural retrofitting, traffic light systems, information and outreach, and public and stakeholder engagement. The proposed framework is currently customized to Switzerland and can be adapted to other regions or geo-energy applications.
\end{abstract}

\section{Keywords}

Induced seismicity, risk, deep geothermal, Enhanced Geothermal Systems (EGS), risk governance 


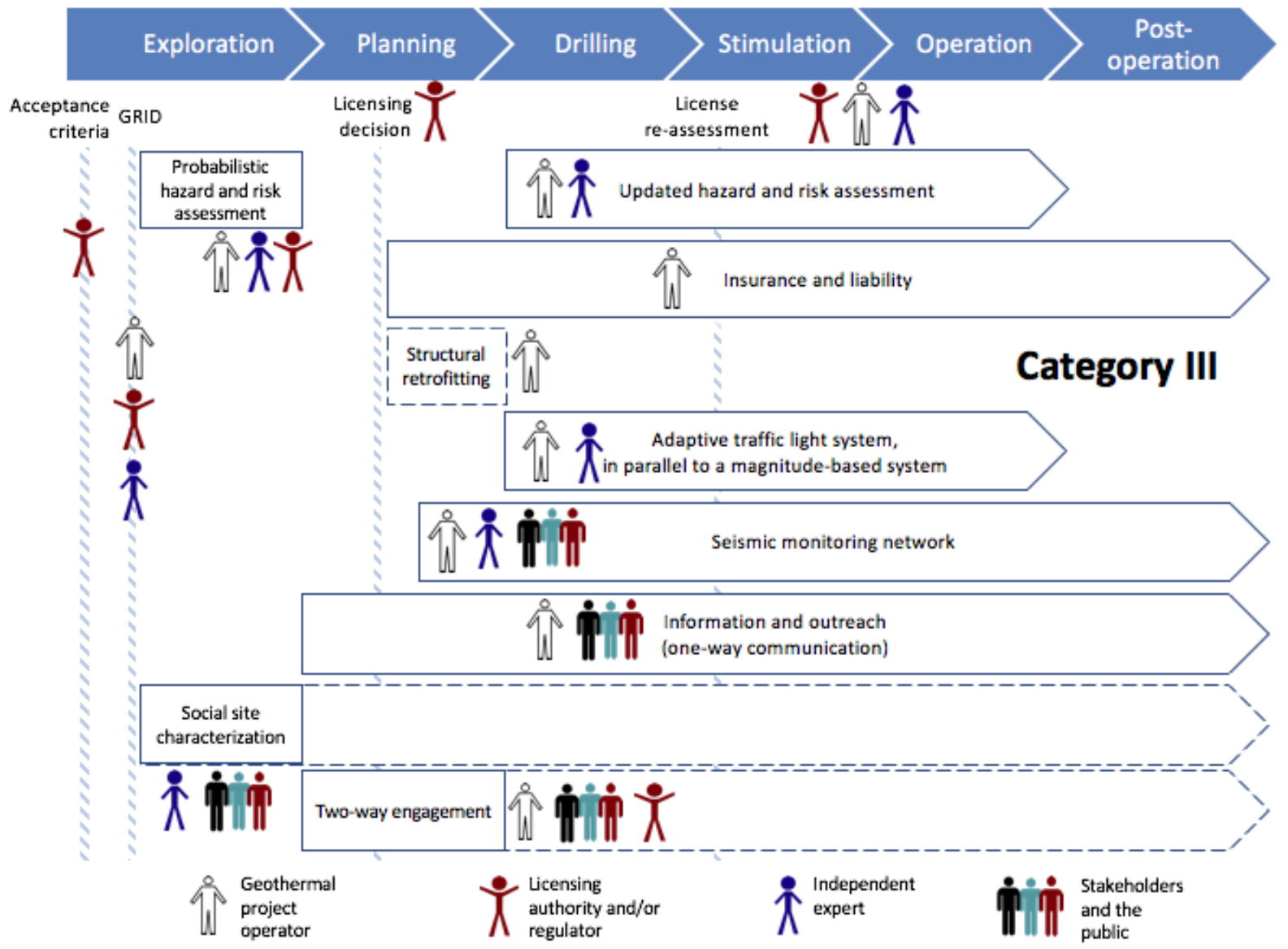




\section{Introduction}

Energy sector decarbonization is necessary to mitigate climate change and requires a portfolio of low-carbon technologies [1, 2]. Geothermal energy for electricity and/or heat generation can make a valuable contribution to diversifying this portfolio. Geothermal energy is not only a low-carbon energy source, but is also available locally and - in contrast to solar or wind energy - independently from variations in weather. The theoretical potential of geothermal energy is vast $[3,4]$. The technical potential is increasingly unlocked through basic research, technological development, and pilot projects.

Underground reservoir creation and operation of fully or partly open geothermal systems that allow fluid exchange in the deep underground may perturb the existing stress field underground and induce potentially damaging seismicity. Although known since the 1920s [5], induced seismicity is a growing concern, not only for geothermal systems [6, 7], but also for conventional oil and gas exploitation [5, 8, 9], wastewater injection [10, 11], hydraulic fracturing [10], mining [12], and geological carbon dioxide storage [13, 14]. For Enhanced Geothermal Systems (EGS), induced seismicity is, in fact, directly related to the economic viability of EGS because the process of enhancing the underground reservoir permeability is correlated with induced earthquakes [15].

A handful of geothermal projects with felt induced seismicity already exist $[6,16,17]$. Three Swiss examples reveal the case-specific nature of induced seismicity. In 2006, the Basel EGS project $(5.0 \mathrm{~km}$ depth) induced felt and damaging events with a maximum magnitude of $M_{L} 3.4$ during the reservoir stimulation, in addition to tens of thousands of micro-earthquakes required for reservoir creation $[18,19]$. The seismicity was widely felt in the city of Basel, with 164,000 inhabitants, and was received unfavorably by both the population and the media. The claims for damage compensation reached 9 million USD [7, 20]. The negative public reaction and the subsequent update of the risk assessment [21] led to the cancelation of the project. In 2013, the St. Gallen hydrothermal project (4.5 km depth) induced an earthquake with a magnitude of $M_{L} 3.5$ during the initial chemical and hydraulic stimulations and the subsequent gas-kick $[15,20]$. Although the seismicity was felt in the city of St. Gallen, with 74,000 inhabitants, there was no notable public pushback [22] and few damages were reported [20]. Due to insufficient water volumes found, coupled with the limited options to increase permeability, and a highly seismically responsive fault zone, the St. Gallen project was still terminated. The Riehen hydrothermal project $(1.25 \mathrm{~km}$ injection, $1.55 \mathrm{~km}$ extraction depth) has been operating since 1989 without concerns about induced seismicity; but seismicity has not been monitored beyond regional monitoring, either [16]. These three Swiss examples illustrate that concern about induced seismicity depends on a combination of hazard, risk, and social concern.

Due to the low magnitudes, EGS induced seismicity has caused no injuries or fatalities to date [15]. However, induced earthquakes in general are emerging as a substantial threat to geothermal and other geo-energy applications around the globe. The M5.6 earthquake near wastewater injection wells in Prague, Oklahoma, in 2011 caused 2 injuries and damages of tens of millions of dollar (USD). Nine fatalities and hundreds of injured were reported for the $M_{w} 5.1$ earthquake near a long-term groundwater extraction site in Lorca, Spain, in 2011, which has been speculated to have been induced. But even without injuries or fatalities, felt, and damaging induced events around EGS sites have led to significant economic losses due to abandoned projects $[7,11]$. The future success of geothermal systems, therefore, crucially depends on how well induced seismicity can be understood, managed, and whether it is acceptable to the society at large, capital investors, (re-)insurance companies, and other stakeholders. 
Not all geothermal systems need the same level of attention to induced seismicity.

\section{Definition of induced seismicity}

In this paper, induced seismicity is defined as all types of seismicity that geothermal projects may contribute to. This encompasses seismicity that primarily releases tectonic stress as well as seismicity that is a direct consequence of the pore pressure changes caused by geothermal activity $[10,11]$. Our definition thus includes seismicity that, in other sources, is also labeled man-made, anthropogenic, triggered, or induced (in a narrower sense).

Even if induced seismic events tend to be smaller than the largest observed natural earthquakes in the area, induced and natural earthquakes are governed by the same physics [23]. This poses a challenge when it comes to distinguishing whether a specific earthquake was natural or induced. A distinction based on a transparent and reproducible definition is important: public reaction and legal implications could be very different and, in contrast to natural earthquakes, induced earthquakes can, to some extent, be mitigated.

Induced seismicity risk is a composite of induced seismicity hazard, local site amplification, exposed structures and population, and their vulnerability [15] (Figure 1). Ellsworth [10] provides an extended overview of the determinants of seismic hazard. Bommer et al. [24] elaborate on the exposure and vulnerability of buildings, infrastructure, and populations. In addition to the hazard and risk dimensions, wider social concern about induced seismicity is also influenced by other aspects, such as trust in project operators or media coverage. Social aspects can amplify or attenuate the risk concern in the eyes of stakeholders and the public $[25,26]$. That is, projects with relatively low hazard and risk may still require attention if social concern is high. 


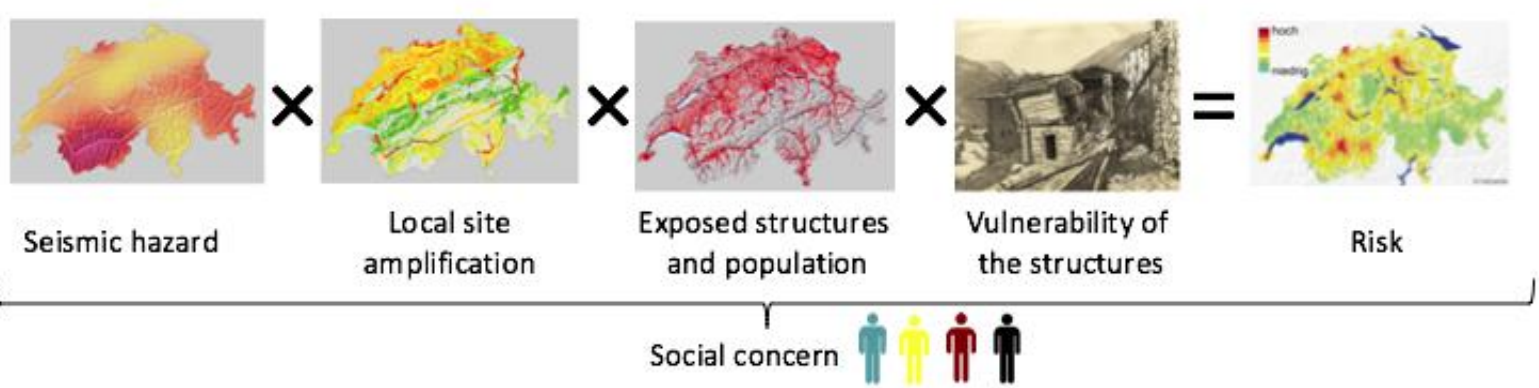

Figure 1. Relationships among induced seismicity hazard, risk, and social concern in the case of Switzerland; redrawn and adapted from [15].

Risk and safety engineering literature often distinguishes between hazard and threat [27]. Hazard is a phenomenon that can cause damage to human health as well as natural and built environments, as in the case with induced seismicity. Threat is the event that releases this hazard, such as happens with high-rate water injection during stimulation. In our proposed framework (Section 4.1), no distinction is made between hazard and threat and they are bundled into the single term of "hazard". A distinction is made between hazard and concern, as is further described in Section 4.1.

\section{Existing approaches to assessment and management of induced seismicity}

\subsection{Regulatory and industry approaches}

This section summarizes existing regulatory and industry approaches to managing induced seismicity of geothermal and other geo-energy projects. To date, Switzerland, the United States and European Union countries have no federal laws or regulations specifically related to geothermal-induced seismicity $[3,28,29]$. Such seismicity is regulated at state and municipal levels and primarily on a project-by-project basis. The United States Programmatic Environmental Impact Statement for geothermal energy [30] does not include induced seismicity, meaning that seismicity needs to be addressed at the project level. For example, in the Geysers deep geothermal project in California, the operator has established a longterm alliance with Lawrence Berkley National Laboratory, local stakeholders, and the public. The adopted seismicity management measures include seismic monitoring, publically available seismicity datasets, and bi-annual stakeholder meetings [29]. Looking at other geoenergy applications, after seismicity concerns, Ohio has added new permitting conditions for hydraulic fracturing that require seismic monitoring for wells at $\leq 3$ miles distance to known faults and temporary injection suspension after M1 [29]. In California seismic monitoring for hydraulic fracturing is also required and, in the case of $\mathrm{M} 2.7$, the injection must be suspended for investigation. In Alberta and British Columbia, in Canada, hydraulic fracturing activities are required to monitor seismicity, too, if seismicity has occurred previously. Traffic light systems need to bet set up and seismicity above M2 must be reported [29]. The U.S. Environmental Protection Agency has prepared an online resource that summarizes regulatory requirements in various states and for various well types with respect to the prevention of ground water pollution. Induced seismicity is, in parts, included too, but not for geothermal applications.

European Union Directives on Environmental Impact Assessment (2014/52/EU), hydrocarbon licensing (94/22/EC), or groundwater protection (2006/118/EC) set the broad regulatory framework for using the deep underground sources, but do not touch on induced seismicity in particular. The Legislative Decree 22 of 11/02/2010 in Italy regulates the use of 
geothermal energy, assigning regions with permitting and review procedures according to environmental impact regulations [28]. In Germany there are no laws specific to geothermal energy, but the projects require mining and building permits as well as a license under the Water Act [28]. The permitting process includes an operation plan, where the mining authority can add conditions. For example, after seismicity increased in the Landau geothermal plant in Germany, the mining authority requested an adjustment of the operation plan and the installation of a monitoring system, a reduction of injection pressure, and the acquisition of higher level of insurance coverage [28]. In Switzerland, the use of the underground lacks federal regulation and thus falls under the responsibility of the cantons (Swiss states) [3]. For plants above $5 \mathrm{MW}_{\text {th }}$ of capacity an environmental impact assessment based on existing procedures needs to be conducted. Existing norms, codes, or recommendations from other risk issues are primarily transferred in Switzerland and other countries to regulate induced seismicity. Majer et al. [31] and Bommer et al. [24] provide overviews of acceptable limits of ground motion, building damage, inference with other industrial, commercial, research and medical activities, and human exposure to groundborne vibrations.

On a parallel track, a series of guidelines and good-practice recommendations have been developed for managing induced seismicity. Some of them stem from joint industry work, such as operating practices of the Canadian Association of Petroleum Producers [32] or the framework of the American Exploration and Production Council [33]. Other goodpractice recommendations have been developed by research and public administrations and are reviewed in Section 3.2.

\subsection{Existing good-practice frameworks}

Several good-practice frameworks and recommendations for assessment and management of induced seismicity exist. Table 1 provides a summary of what these frameworks cover. The most elaborate framework to date has been developed by the US Department of Energy for EGS projects [31,34]. This framework has both breadth and depth: it covers elements from preliminary screening to seismic hazard and risk assessment, monitoring and management, as well as outreach. Walters et al. [35] introduce risktolerance matrices for seismicity triggered by wastewater injection and hydraulic fracturing. Injection sites are rated on the basis of their operational characteristics and exposure of critical facilities and infrastructure, environment, and populations. Walters et al. also suggest case-specific traffic light systems. The framework of Bommer et al. [24] focuses on estimating and mitigating the risk rather than only the hazard of induced seismicity. The authors argue that the success of induced seismic hazard control has not yet been proven and the focus should shift to adaptation measures, such as insurance, structural retrofitting, or, at times, relocation of the exposed population. Wiemer et al. [15] provide a list of recommendations, but not an integrated framework, for hazard and risk assessment, seismic monitoring, and traffic light systems. Zoback [36] proposes a five-point checklist for induced seismicity management: avoiding active faults, installing seismic monitoring, minimizing pore pressure changes at depth, establishing modification protocols, and being ready to alter plans. Hoşgör et al. [37] integrate the geothermal resource, seismic hazard, and risk considerations for identifying suitable sites for geothermal projects in the U.S.

Although induced seismicity does not concern all geothermal projects, none of the existing frameworks provide clear guidance for geothermal project operators, licensing authorities, or regulators as to how to pre-assess whether their project will be prone to induced seismicity and what assessment and management measures need to be planned. Majer et al. [34] suggest a preliminary screening of sites to categorize them as having a very 
233 low, low, medium, or high risk of induced seismicity. However, the exact method is not 234 provided, preventing transparency, reproducibility, and transferability of such a screening. 235 The categories outlines by Majer et al. are also applicable to EGS only and do not refer to 236 other types of geothermal systems. The risk-tolerance matrices of Walters et al. [35] are 237 applicable to fluid disposal and hydraulic fracturing, but not to geothermal systems. After all, 238 none of the existing frameworks consider how public and social concern may elevate the 239 overall concern about induced seismicity. GRID, proposed in Section 4, fills this gap.

Table 1. Existing good-practice frameworks for assessment and management of induced seismicity

\begin{tabular}{|c|c|c|c|c|c|c|}
\hline \multirow[b]{2}{*}{ Framework } & \multicolumn{2}{|c|}{ Majer et al. } & \multirow[b]{2}{*}{$\begin{array}{l}\text { Walters } \\
\text { et al. [35] }\end{array}$} & \multirow[b]{2}{*}{$\begin{array}{l}\text { Bommer, } \\
\text { Crowley } \\
\text { and } \\
\text { Pinho } \\
\text { [24] }\end{array}$} & \multirow[b]{2}{*}{$\begin{array}{l}\text { Wiemer, } \\
\text { Kraft and } \\
\text { Landtwing } \\
\text { [15] }\end{array}$} & \multirow[b]{2}{*}{$\begin{array}{l}\text { Proposed } \\
\text { framework } \\
\text { (Section } \\
5.2 \text { ) }\end{array}$} \\
\hline & {$[34]$} & [31] & & & & \\
\hline Scope & geothermal & geothermal & $\begin{array}{l}\text { fluid } \\
\text { injection, } \\
\text { hydraulic } \\
\text { fracturing }\end{array}$ & $\begin{array}{c}\text { all } \\
\text { induced } \\
\text { seismicity }\end{array}$ & geothermal & geothermal \\
\hline Country of application & USA & USA & generic & generic & Switzerland & Switzerland \\
\hline Initial screening & brief & detailed & detailed & - & - & detailed \\
\hline \multicolumn{7}{|l|}{ Seismic hazard } \\
\hline \multicolumn{7}{|l|}{ Assessment } \\
\hline $\begin{array}{l}\text { - Empirical seismic } \\
\text { hazard study }\end{array}$ & brief & detailed & brief & brief & brief & brief \\
\hline $\begin{array}{l}\text { - Probabilistic } \\
\text { seismic hazard } \\
\text { study }\end{array}$ & brief & detailed & brief & brief & brief & brief \\
\hline - $\quad$ Secondary hazards & brief & brief & - & brief & - & brief \\
\hline \multicolumn{7}{|l|}{ Management } \\
\hline - $\quad$ Seismic monitoring & brief & detailed & brief & brief & brief & brief \\
\hline $\begin{array}{l}\text { - Magnitude-based } \\
\text { traffic light } \\
\text { systems }\end{array}$ & brief & brief & brief & brief & brief & brief \\
\hline $\begin{array}{ll}\text { - } & \text { Risk-based traffic } \\
\text { light systems }\end{array}$ & brief & brief & brief & brief & brief & brief \\
\hline $\begin{array}{l}\text { - Adaptive risk- } \\
\text { based traffic light } \\
\text { systems }\end{array}$ & - & - & brief & brief & brief & brief \\
\hline \multicolumn{7}{|c|}{ Seismic risk (exposure and vulnerability of structures and population) } \\
\hline \multicolumn{7}{|l|}{ Assessment } \\
\hline $\begin{array}{l}\text { - Macroseisimic } \\
\text { intensity- or } \\
\text { engineering-based } \\
\text { risk study }\end{array}$ & brief & detailed & brief & detailed & - & brief \\
\hline \multicolumn{7}{|l|}{ Management } \\
\hline $\begin{array}{ll}\text { - } & \text { Building } \\
\text { monitoring }\end{array}$ & - & in detail & - & brief & - & brief \\
\hline $\begin{array}{l}\text { - Insurance and } \\
\text { liability } \\
\end{array}$ & brief & brief & - & brief & - & brief \\
\hline $\begin{array}{ll}\text { - } & \text { Structural } \\
& \text { retrofitting } \\
\end{array}$ & - & - & - & detailed & - & brief \\
\hline $\begin{array}{l}\text { - Relocation of the } \\
\text { population }\end{array}$ & - & - & - & brief & - & $-*$ \\
\hline \multicolumn{7}{|l|}{ Social concern } \\
\hline \multicolumn{7}{|l|}{ Assessment } \\
\hline - $\quad$ Social site & - & detailed & - & - & - & brief \\
\hline
\end{tabular}




\begin{tabular}{|c|c|c|c|c|c|c|}
\hline characterization & & & & & & \\
\hline Management & & & & & \\
\hline $\begin{array}{l}\text { Information and } \\
\text { outreach }\end{array}$ & brief & detailed & - & - & - & brief \\
\hline $\begin{array}{l}\text { Two-way } \\
\text { engagement }\end{array}$ & - & detailed & - & - & - & brief \\
\hline
\end{tabular}

* Relocation of the exposed population is not included in the proposed framework because it is considered unfeasible in densely populated Switzerland.

242

243

244

245

246

247

248

249

250

251

252

253

254

255

256

257

258

259

260

261

262

263

264

265

266

267

268

269

270

271

272

273

274

275

276

277

278

279

280

281

282

283

In addition to induced seismicity frameworks, more generic approaches exist for assessing and managing complex risks with deep uncertainties and social concern potential. An analytic-deliberative approach to risk [38-40] suggests a process of iterating between the 'factual' risk analysis and deliberation with the interested and affected parties. This approach is further elaborated on in other publications [40-42]. These generic frameworks, however, have not yet been 'translated' to the case of induced seismicity. Our proposed framework of risk governance (Section 5.2) applies this analytic-deliberative approach to the induced seismicity of geothermal projects.

\section{Geothermal Risk of Induced seismicity Diagnosis (GRID)}

\subsection{The GRID concept and process}

The Geothermal Risk of Induced seismicity Diagnosis (GRID) is a transparent, reproducible and transferable approach for the initial screening of geothermal energy projects in terms of induced seismicity concerns. GRID is based on indicators of seismic hazard, risk (secondary hazards, exposure, and vulnerability), and social concern (public or stakeholder concern, and trust). The GRID scores are dependent on, but not exactly proportional to, the level of seismic hazard or risk, which is often not known in a fully quantitative way when GRID is assessed. GRID reflects the concern level rather than the hazard or risk level, assuming that higher concern requires more involved measures of risk governance. For example, in line with the social amplification of risk $[25,26]$, social concerns, such as lack of trust in the operator or widespread public worry about induced seismicity, increase GRID scores. That means that projects with relatively low hazard and/or risk, but high social concern would still need some type of hazard and risk assessment or monitoring in order to address the social concern. Another example is the separation between natural and induced seismicity. The influence of natural seismicity on the induced seismic hazard is debated. Higher background seismicity is still assumed to increase GRID scores because more measures are required to distinguish an induced event with confidence for liability purposes. On the other hand, people in low seismicity regions may react more sensitively to even low levels of shaking.

GRID, by design, includes relatively simple, rule-of-thumb scores. The simplicity is adequate in order to enable a fast, transparent, reproducible, and transferable method for characterizing a geothermal project at an early stage. All data required for GRID are available in regional statistics or can be estimated by experts before the first well is drilled. As induced seismicity is an emerging issue, geothermal project operators or regulators may not yet have extensive expertise in seismicity. A simple GRID approach is thus also advantageous: GRID evaluation and associated discussions are helpful, not only for defining the project category, but also for thinking through the various relevant elements of induced seismicity.

We recommend that GRID scores be evaluated at an early project planning stage, before the drilling or communicating with the affected members of society. However, GRID 
scores can be revisited throughout the different project stages as new knowledge emerges. At least three parties would ideally be involved: the project operator, the licensing authority/regulator, and one or two independent experts. These parties could seek professional/expert advice, if needed, for evaluating specific GRID indicators. Values that are unknown or that can change during the course of the project (e.g., injection rates) can be given with uncertainty bounds. Since some indicators, especially those related to social concern, are defined qualitatively, the GRID scores need to be mapped by every individual party separately, rather than converging all the views into a single average score.

Drawing from recommendations by Mastrandrea et al. [43], we suggest that:

- Each party writes down its individual GRID assessments before entering into a group discussion;

- The results of the individual assessments are shown and discussed in the group, especially addressing the points where assessments diverge;

- Each party can revise their individual assessments after the group discussion and this revision needs to be documented. The GRID scores should not be aggregated across the parties in order to transparently document the remaining points of judgment divergence;

- The licensing authority/regulator could decide on the final category of the project based on these GRID scores. One suitable decision heuristic in line with a precautionary approach, for example, is to choose the category where the highest GRID score of any party falls.

\subsection{Evaluation of the GRID scores}

Table 2 provides a summary of indicators used to evaluate GRID. All indicators are assigned values of 0 (little concern), 1 (medium concern), or 2 (high concern). The definition and values of indicators are, at the moment, somewhat customized to Switzerland. The transferability of GRID to other countries is discussed in Section 6.

Table 2. Indicators used in GRID

\begin{tabular}{|c|c|c|c|}
\hline $\begin{array}{ll}\text { SEISMIC } & \text { HAZARD } \\
\text { CONCERN } & \\
\end{array}$ & 0 (little concern) & 1 (medium concern) & 2 (high concern) \\
\hline Depth of the reservoir & $<1 \mathrm{~km}$ & $1-3 \mathrm{~km}$ & $>3 \mathrm{~km}$ \\
\hline $\begin{array}{l}\text { Cumulative injection } \\
\text { volume during stimulation }\end{array}$ & $<1,000 \mathrm{~m}^{3}$ & $1,000-10,000 \mathrm{~m}^{3}$ & $>10,000 \mathrm{~m}^{3}$ \\
\hline $\begin{array}{l}\text { Daily injection or extraction } \\
\text { volume during operation }\end{array}$ & $\begin{array}{l}<1,000 \mathrm{~m}^{3} / \text { day injection or } \\
<5,000 \mathrm{~m}^{3} / \text { day extraction }\end{array}$ & $\begin{array}{l}1,000-10,000 \mathrm{~m}^{3} / \text { day injection } \\
\text { or } 5,000-50,000 \mathrm{~m}^{3} / \text { day } \\
\text { extraction }\end{array}$ & $\begin{array}{l}>10,000 \mathrm{~m}^{3} / \text { day injection or } \\
>50,000 \mathrm{~m}^{3} / \text { day extraction }\end{array}$ \\
\hline Rock type & Sediments & $\begin{array}{l}\text { Within } 500 \text { meters from the } \\
\text { crystalline basement }\end{array}$ & Crystalline \\
\hline $\begin{array}{l}\text { Separation between } \\
\text { background and induced } \\
\text { seismicity }\end{array}$ & $\begin{array}{l}\leq 0.6 \mathrm{~m} / \mathrm{s}^{2} \text { dimensioning value } \mathrm{a}_{\mathrm{gd}} \\
\text { from [44], defined as maximum } \\
\text { PGA on Ground Class A of natural } \\
\text { seismicity with a } 475 \text {-year return } \\
\text { period }\end{array}$ & $\begin{array}{l}<1.3 \mathrm{~m} / \mathrm{s}^{2} \text { dimensioning value } \\
\mathrm{a}_{\mathrm{gd}} \text { from [44] }\end{array}$ & $\begin{array}{l}\geq 1.3 \mathrm{~m} / \mathrm{s}^{2} \text { dimensioning value } \mathrm{a}_{\mathrm{gd}} \text { from } \\
{[44]}\end{array}$ \\
\hline Fluid injection pressure & $<0.1 \mathrm{MPa}$ & $0.1-1 \mathrm{MPa}$ & $>1 \mathrm{MPa}$ \\
\hline $\begin{array}{l}\text { Distance to known and } \\
\text { potentially active faults } \\
\text { with length greater than } 3 \\
\text { km }\end{array}$ & $>5 \mathrm{~km}$ & $2-5 \mathrm{~km}$ & $<2 \mathrm{~km}$ \\
\hline $\begin{array}{l}\text { CONCERN ABOUT } \\
\text { SECONDARY HAZARDS, } \\
\text { EXPOSURE AND } \\
\text { VULNERABILITY } \\
\text { (within a radius of } 5 \mathrm{~km} \text { ) }\end{array}$ & 0 (little concern) & 1 (medium concern) & 2 (high concern) \\
\hline $\begin{array}{l}\text { Local site amplification } \\
\text { (within a radius of } 5 \mathrm{~km} \text { ) }\end{array}$ & $\begin{array}{l}\text { No buildings or infrastructure on } \\
\text { soft soils (Ground Class D, E, F in }\end{array}$ & $\begin{array}{l}<10 \% \text { of buildings or } \\
\text { infrastructure on soft soils }\end{array}$ & $\begin{array}{l}\geq 10 \% \text { of buildings or infrastructure on } \\
\text { soft soils (Ground Class D, E, F in [44]) }\end{array}$ \\
\hline
\end{tabular}




\begin{tabular}{|c|c|c|c|}
\hline & $[44])$ & (Ground Class D, E, F in [44]) & \\
\hline $\begin{array}{l}\text { Exposed population } \\
\text { (within a radius of } 5 \mathrm{~km} \text { ) }\end{array}$ & Remote (<100 inhabitants) & $\begin{array}{l}\text { Rural (100-20,000 } \\
\text { inhabitants) }\end{array}$ & Urban (>20,000 inhabitants) \\
\hline $\begin{array}{l}\text { Industrial or commercial } \\
\text { activity (within a radius of } 5 \\
\mathrm{~km} \text { ) }\end{array}$ & Low activity & $\begin{array}{l}\text { Medium activity ( } \geq 1 \\
\text { enterprise with } 100-499 \\
\text { employees or } \geq 1 \text { industrial } \\
\text { installation of a particular } \\
\text { value) }\end{array}$ & $\begin{array}{l}\text { High activity ( } \geq 5 \text { enterprises with } 100 \text { - } \\
499 \text { employees or }>1 \text { enterprise with } \\
\text { over } 500 \text { employees or } \geq 2 \text { industrial } \\
\text { installation of a particular value) }\end{array}$ \\
\hline $\begin{array}{l}\text { Importance of buildings and } \\
\text { infrastructure (within a } \\
\text { radius of } 5 \mathrm{~km} \text { ) }\end{array}$ & $\begin{array}{l}\text { No buildings or infrastructure of } \\
\text { Class II or III, as defined in [44] }\end{array}$ & $\begin{array}{l}\text { Buildings or infrastructure of } \\
\text { Class II [44]; no buildings or } \\
\text { infrastructures of Class III [44] }\end{array}$ & $\begin{array}{l}\text { Buildings and infrastructure of Class III } \\
\text { [44] }\end{array}$ \\
\hline $\begin{array}{l}\text { Infrastructures with } \\
\text { considerable environmental } \\
\text { risk (within a radius of } 5 \\
\mathrm{~km} \text { ) }\end{array}$ & None & - & One or more \\
\hline $\begin{array}{l}\text { Unreinforced cultural } \\
\text { heritage (within a radius of } \\
5 \mathrm{~km} \text { ) }\end{array}$ & $\begin{array}{l}<5 \% \text { buildings listed as important } \\
\text { local, regional or national } \\
\text { heritage sites }\end{array}$ & $\begin{array}{l}5-10 \% \text { buildings listed as } \\
\text { important local, regional or } \\
\text { national heritage sites }\end{array}$ & $\begin{array}{l}>10 \% \text { buildings listed as important local, } \\
\text { regional or national heritage sites; or any } \\
\text { buildings listed as important } \\
\text { international heritage sites }\end{array}$ \\
\hline $\begin{array}{l}\text { Susceptibility to secondary } \\
\text { hazards (within a radius of } 5 \\
\mathrm{~km} \text { ) }\end{array}$ & Very low & Exists & High \\
\hline SOCIAL CONCERN & 0 (little concern) & 1 (medium concern) & 2 (high concern) \\
\hline $\begin{array}{l}\text { Potential for concern in the } \\
\text { general population }\end{array}$ & None & Exists & Significant \\
\hline $\begin{array}{l}\text { Vulnerable or strongly } \\
\text { opposing stakeholders }\end{array}$ & None & Exist & Significant \\
\hline $\begin{array}{l}\text { Negative experiences with } \\
\text { similar projects }\end{array}$ & None & Exist & Significant \\
\hline $\begin{array}{l}\text { Lack of trust in the project } \\
\text { operators or authorities }\end{array}$ & None & Exists & Significant \\
\hline $\begin{array}{l}\text { Benefits to the local } \\
\text { community }\end{array}$ & $\begin{array}{l}\text { Direct benefits with or without } \\
\text { monetary compensation }\end{array}$ & Monetary compensation only & None \\
\hline
\end{tabular}

The concern about seismic hazard in GRID is characterized using these indicators:

- Depth. Deeper systems are generally believed to produce more induced earthquakes as a consequence of the strength profile of the Earth's crust. Differential stresses increase with depth. Natural earthquakes are, likewise, less frequent in the top 1-3 $\mathrm{km}$ of the Earth's crust. Three levels are thus distinguished: less than $1 \mathrm{~km}$ depth; 1-3 $\mathrm{km}$ depth; and more than $3 \mathrm{~km}$ depth.

- Cumulative injection volume during stimulation. The larger the volume of rock affected, the more events are likely to happen. This is the first-order geometrical effect. Whether the maximum possible event size also scales with the volume or fault area affected is currently debated $[45,46]$. For GRID, three levels are distinguished: volumes below $1,000 \mathrm{~m}^{3}$; those between 1,000 and $10,000 \mathrm{~m}^{3}$; and volumes of more than $10,000 \mathrm{~m}^{3}$.

- Daily injection or extraction volume during operation: Based on the same logic as above, the effect of the injected or extracted fluid volume during operations is divided into three levels: injection volumes below $1,000 \mathrm{~m}^{3} /$ day or extraction volumes below $5,000 \mathrm{~m}^{3} /$ day; injection volumes between 1,000 and $10,000 \mathrm{~m}^{3} /$ day or extraction volumes between 5,000 and $5,000 \mathrm{~m}^{3} /$ day; and injections volumes of more than $10,000 \mathrm{~m}^{3} /$ day or extraction volumes of more than $50,000 \mathrm{~m}^{3} /$ day.

- Rock type. Crystalline basement rocks are typically believed to be more seismogenic than sedimentary rocks [16], and seismicity is often observed near or below the basement. Three levels for GRID are defined: sediments; areas within 500 meters from the crystalline basement; and the crystalline basement.

- Separation between background and induced seismicity: Although induced earthquakes are usually smaller than the largest observed natural earthquakes in a given area [23], induced seismicity is not necessarily less likely in low natural 
seismicity areas [16]. Low natural seismicity, however, allows for a more straightforward distinction as to whether a specific earthquake is induced, for liability purposes. The current Swiss structural design norms [44] defines three categories of natural seismicity, based on the dimensioning value of ground acceleration $\left(\mathrm{a}_{\mathrm{gd}}\right)$. This dimensioning value is equal to the maximum Peak Ground Acceleration (PGA) on Ground Class A with a 475-year return period. This metric is also used in GRID to distinguish between low and high natural seismicity areas: $a_{g d}$ is below $0.6 \mathrm{~m} / \mathrm{s}^{2} ; 0.6$ $1.3 \mathrm{~m} / \mathrm{s}^{2}$; and above $1.3 \mathrm{~m} / \mathrm{s}^{2}$. Potential GRID applications in other countries will need another indicator, though.

- Fluid injection pressure: Increasing the pore pressure on pre-stressed faults may eventually cause these faults to rupture, releasing a (generally small) fraction of tectonic stresses accumulated over centuries prematurely. In order to reflect on the role of injection pressure, three levels are defined: below $0.1 \mathrm{MPa} ; 0.1-1 \mathrm{MPa}$; and above $1 \mathrm{MPa}$.

- Distance to known and potentially active faults with lengths greater than $\mathbf{3} \mathbf{~ k m : ~}$ Injection into or close to tectonically active faults greatly increases the chance of induced seismicity [36]. Thus, three categories are defined: distances of more than 5 $\mathrm{km}$; distances between 2 and $5 \mathrm{~km}$; and distances of less than $2 \mathrm{~km}$.

In GRID, the concern about seismic risk is evaluated based on the indicators within a radius of $5 \mathrm{~km}$ :

- Local site amplification. Soft soils amplify ground motion more than hard soils. Using the definitions of Swiss structural design norms [44], Ground Class D (deposits of unconsolidated fine sand, silt, and clay exceeding $30 \mathrm{~m}$ of thickness), E (alluvial surface layer of normally consolidated and uncemented gravel and sand and/or moraine as well as Class D soils with a thickness exceeding $30 \mathrm{~m}$ ), and F (deposits of structurally-sensitive and organic deposits with a thickness exceeding $10 \mathrm{~m}$ ) are considered of concern and defined as soft soils for GRID. Three categories are distinguished: no buildings or infrastructures on soft soils of Ground Class D, E, or F [44]; less than $10 \%$ of buildings or infrastructures on soft soils; and more than $10 \%$ of these structures on soft soils.

- Exposed population. Exposed population is used as a proxy for the amount of people, buildings, and infrastructure exposed. Three categories are distinguished: remote, with less than 100 inhabitants; rural, with 100 - 20,000 inhabitants; and urban, with more than 20,000 inhabitants.

- Industrial and commercial activity. In order to account for the economic activity in a considered region, industrial and commercial activity is used as a proxy. It is defined in terms of the presence of large enterprises and industrial installations of a particular value (e.g., large factories or large power plants). Three categories are defined: low activity; medium activity with at least one enterprise with 100-499 employees or at least one industrial installation of a particular value; and high activity with at least five enterprises with 100-499 employees or at least one enterprise with more than 500 employees or at least two industrial installation of a particular value;

- Importance of buildings and infrastructure. Importance classes from the Swiss structural design norms [44] are used to approximate the seismic vulnerability of buildings and civil infrastructure, including human occupancy, environmental risk, function, and value of the facility. Class I includes residential, office, commercial, and industrial buildings without large public gatherings, goods, or installations of a particular value. Hospitals, shopping centers, public administration buildings, bridges 
of considerable importance, retaining walls and slopes close to considerable importance traffic routes, supply, waste disposal, and communication services are assigned to Class II. Class III includes crucial hospitals, construction works for protection in the case of catastrophes (e.g., ambulance garages or fire stations), bridges of great importance, retaining walls and slopes close to great importance traffic routes, and construction works vital for supply, waste disposal and communication. These GRID categories are defined: no buildings or infrastructures of infrastructures are in Class II; buildings or infrastructures are in Class III.

- Infrastructures with considerable environmental risk. This category encompasses infrastructures with considerable environmental risk, such as nuclear power plants, long-term nuclear waste repositories, large hydropower dams, and others. Two categories in GRID are distinguished: no such infrastructure (0, no concern) and one or more such infrastructure types (2, high concern).

- Unreinforced cultural heritage. Based on the Hague Convention for the Protection of Cultural Property in the Event of Armed Conflict [47], four types of cultural heritage buildings are distinguished: cultural property of local importance $(C)$, regional importance (B), national importance (A), and international importance (AA). These categories in GRID are used: less than $5 \%$ of buildings are listed as having local, regional, or national heritage importance; $5-10 \%$ of buildings are listed as having local, regional or national heritage importance; and more than $10 \%$ of buildings are listed as having local, regional or national heritage importance or any buildings as having international heritage importance.

- Susceptibility to secondary hazards. Secondary hazards [48], such as landslides [49], liquefaction [50], fire [51], or tsunamis in enclosed water bodies [52], increase the overall risk posed by induced seismicity. In GRID, susceptibility to secondary hazards is defined as: very low; exists; and high.

The social concern in GRID is based on these indicators at an early planning stage:

- Potential for concern in the general population. This indicator covers evidence of existing or potentially emerging concern in the general population about induced seismicity [53,54], locally, regionally, or nationally. Such evidence could be growing momentum of opposition or negative media coverage. Three categories are defined: no concerns; some concerns exist; significant concerns exist.

- Vulnerable or strongly opposing stakeholders: A microdiversity of views among the public and stakeholders exists [55]. But even small groups of strong opposition, vulnerable populations, or powerful actors can be enough to oppose a project. This indicator thus describes whether there is evidence of such vulnerable or opposing groups, who think that their well-being is particularly negatively affected by induced seismicity. As compared to the previous point, this 'Vulnerable or opposing stakeholders' indicator refers to specific stakes and groups. Three categories are defined: no vulnerable or strongly opposing stakeholders; some exist; or significant groups of vulnerable or strongly opposing stakeholders exist.

- Negative experiences with similar projects: Previous negative experiences in the community, such as large failed projects, inadequate management of other industrial risks, intense and critical media discussions, as well as previous negative experiences with induced seismicity in the vicinity, indicate of a potential for concern $[56,57]$. Three categories are defined: no negative experiences; some experiences exist; or significant experiences exist. 
- Lack of trust in the project operator or authorities: Lack of trust increases the chance of negative societal responses $[58,59]$. This category is divided into three categories: no concerns about lack of trust; some concerns exist; or significant concerns exist.

- Benefits to the local community: Long-term direct benefits to the community, such as heat supply or jobs directly related to the project, as well as monetary compensation, such as royalties, increase the acceptance of the geothermal projects and their risks $[53,57]$. Three categories are defined: there are direct benefits with or without monetary compensation; there is monetary compensation only; or there are no direct benefits or monetary compensation.

Once all the indicators from Table 2 are rated, they are depicted on the GRID graph in Figure 2. The indicators of seismic hazard are summed and plotted on the horizontal axis. The indicators of concern about secondary hazards, exposure and vulnerability are summed and plotted on the vertical axis. The indicators of social concern are summed as well, but they are assumed to diagonally increase the GRID score by adding 0.5 on the vertical axis and 0.5 on the horizontal axis per each point of social concern. Figure 2 provides an illustration. Differentiation of the scores with and without social concern is recommended in order to enable a discussion of the 'factual' hazard and risk dimensions versus social concern. The scores of every individual party, including uncertainty bounds, need to be depicted separately, as described in Section 4.1.

In contrast to the approach of Walters et al. [35], GRID scores define hard thresholds between the different project categories. Such an approach is useful for reducing ambiguity and facilitating decision-making. The thresholds have been derived from the GRID application to existing and hypothetical geothermal projects (Section 4.2). In between Categories 0 and III, the category switch occurs with every additional sum of four points for hazard and risk concerns. High social concern (the sum of four points) also shifts the project to the next category.

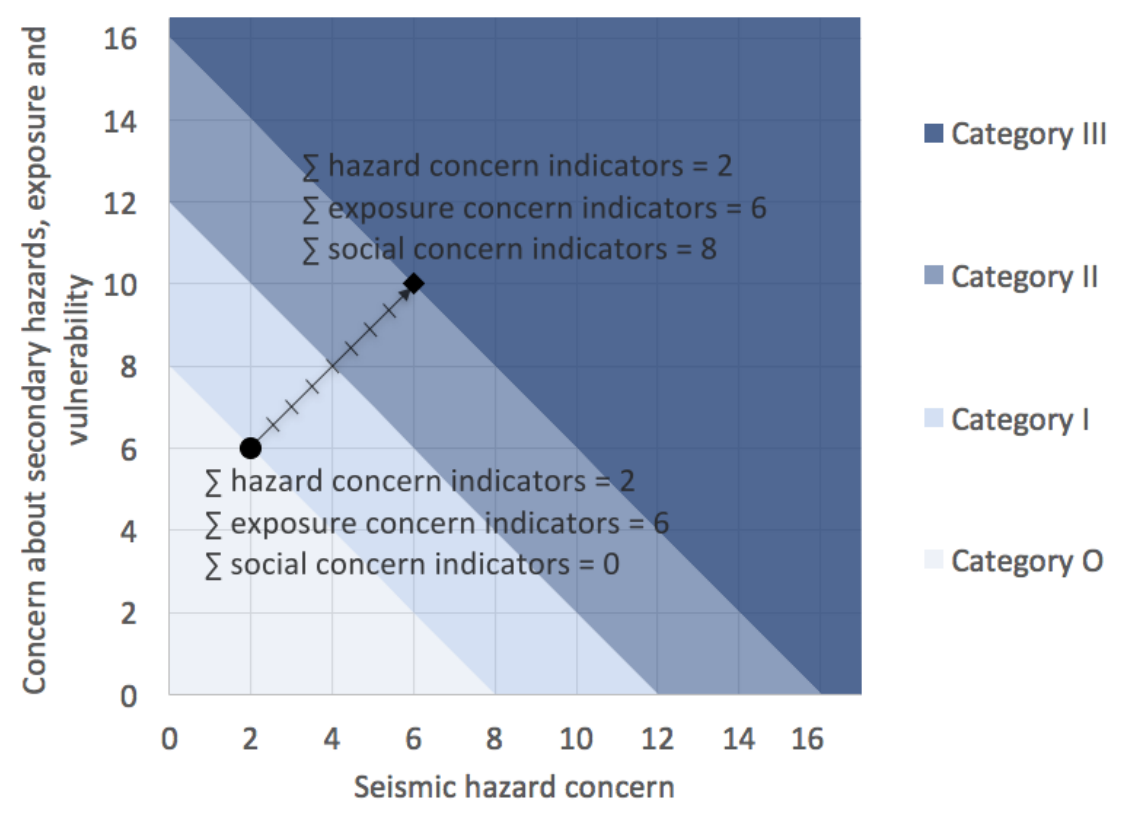

Figure 2. GRID graph and an illustration

The category of a specific geothermal energy project is then derived from Figure 2: 
- Category 0: Induced seismic hazard, risk and social concerns are very low or absent and no dedicated induced seismicity risk governance is needed. Typical Category 0

\subsection{GRID illustration}

These categories are used to tailor the induced seismicity risk governance measures (Section 5). projects are, for example, closed systems where no fluids are exchanged with the underground, deep heat pumps, or exploration drills that are situated in a low-risk area without signs of social concerns.

- Category I: Perturbations of the stress field in the underground may be expected, but damaging events are very unlikely and there is no significant social concern to be addressed. Typical projects in this category are hydrothermal projects in existing aquifers, with a depth of $0.5-3 \mathrm{~km}$, if they do not target active fault systems, perform substantial stimulation, and if they are located in a low-risk area without social concern potential.

- Category II: Induced seismicity is possible, and damaging events and social concern cannot be excluded. Typical projects in this category may be hydrothermal projects in existing aquifers with depths of more than $3 \mathrm{~km}$, possibly near known fault systems, but that do not plan to perform substantial stimulation, and perturb the pore pressure and stress outside the immediate vicinity of the well. These projects may also be located in medium- to high-risk areas or can show evidence of social concern.

- Category III: Induced seismicity is likely, damaging events and significant social concerns are possible and require thorough risk governance measures. Typical projects in this category are EGS projects in basement rocks with depths below $3 \mathrm{~km}$, possibly near known fault systems, and plans to perform substantial stimulation and reservoir enhancement. Seismicity will certainly occur and felt events are likely. Even in low-risk, low-social concern areas, these projects require substantial risk assessment, monitoring, mitigation, and public engagement.

GRID is illustrated by rating four geothermal projects: Basel, St. Gallen, and Riehen projects as well as a hypothetical Basel-type project situated in a low-risk area with high social concern. These projects are described in detail in Table 3. It is assumed that three experts rated these four projects at an early planning stage, before any drilling or communication with the society. Their detailed judgments are given in the Supplementary Information section.

Table 3. Four geothermal projects for GRID illustration

\section{Basel project}

The Basel project was one of the first commercial EGS projects. Initial reservoir stimulation was performed in 2006. A reservoir in the crystalline basement at $5 \mathrm{~km}$ depth was planned. The area has a moderate level of natural seismicity with $\mathrm{a}_{\mathrm{gd}}=1.3 \mathrm{~m} / \mathrm{s}^{2}$ [44].

The EGS plant was situated in the city of Basel with 164,000 inhabitants in the historic old town, and a significant pharmaceutical industry, among other industries. At the time of siting, both EGS technology and induced seismicity were rather unknown. No distinctive signs of social concern existed at the time

\section{St. Gallen project}

The St. Gallen project was a hydrothermal project (not EGS), targeting a pre-existing $30 \mathrm{~km}$-long fault at $4.5 \mathrm{~km}$ of depth expected to exhibit high permeability. Due to the lack of recent seismicity $\left(a_{g d}=0.6 \mathrm{~m} / \mathrm{s}^{2}\right)$, the fault was considered inactive. The injectivity tests were conducted in 2013.

The project was situated near the city of St. Gallen with 76,000 inhabitants at that time, some industrial and commercial activity, as well as a UNESCO-listed abbey district. At the time of planning, social concerns about induced seismicity were present, especially due to the negative Basel experience. At the same time 
of planning.

During the initial stimulation, when the maximum injection rate of $57 \mathrm{l} / \mathrm{s}$ was reached, $M_{L} 2.6$ occurred. Due to the traffic light system, the injection rate was then reduced, and after a few hours it totally stopped. An event of $M_{L} 3.4$ occurred about 5 hours later. This event was widely felt by the population in the city of Basel. Insurance claims for damage compensation, mostly fine cracks in plaster, reached about 9 million USD. After the updated risk assessment in 2009, the project was cancelled.

Further information can be found in other sources $[15,18,60]$. the St. Gallen project was, to some extent, framed as an antipode to the Basel project. The plant was part of the St. Gallen energy strategy and aimed at generating $30 \mathrm{MW}_{\text {th }}$ of heat for the district heating system and $5 \mathrm{MW}_{\mathrm{el}}$ of electricity.

During the initial injectivity test, the events of $M_{L}$ 1.6 and 2.2 occurred. The traffic light system, however, was not engaged as planned in response to seismic activity during well control operations following a gas kick $\left(95 \% \mathrm{CH}_{4}\right)$. The gas content and wellhead pressure increased to levels possibly dangerous to the equipment. The largest event that occurred was $M_{L}$ 3.5. The public reaction, however, was rather calm. Only a few dozen damage claims were received.

Further information can be found in other sources $[15,20,22,61]$.

\section{Riehen project}

The Riehen project is a hydrothermal (not EGS) project that started operating in 1989 and produced heat seasonally since 1994 . The plant's injection well reaches $1.25 \mathrm{~km}$ of depth and the extraction well reaches $1.55 \mathrm{~km}$. Peak injection volume during operation is $18 \mathrm{l} / \mathrm{s}$ at $1.2 \mathrm{MPa}$ pressure. The area has a moderate level of natural seismicity $\left(\mathrm{a}_{\mathrm{gd}}=1.3 \mathrm{~m} / \mathrm{s}^{2}\right)$.

The plant is situated in the town of Riehen with 20,000 inhabitants. The city of Basel, where the Basel EGS was sited, is $5 \mathrm{~km}$ away. At the time of planning, there were no concerns about technology or induced seismicity in Riehen.

Although the project has been operating for more than 20 years, there has been no felt seismicity reported. However, the micro-seismicity has not been monitored specifically either.

Further information is provided in other sources [16].

Basel-like project in a low-risk area with high social
concern (hypothetical case)

This hypothetical case is assumed to be similar to the Basel plant (at the top left corner of this Table). It is an EGS plant, situated in an area with moderate natural seismicity.

In contrast to Basel, it is assumed that the plant is situated in a region with low risk, such as a rural area with less than 100 inhabitants in a radius of $5 \mathrm{~km}$. No significant industrial activity, critical infrastructure, or heritage sites are present in the area.

It is assumed that this project is conducted at a time of high social concern about induced seismicity and the project itself. There is a lack of trust in the project operator and no benefits to the local community.

Figure 3 shows the GRID results for the four projects. The Basel and St. Gallen projects, whether considering social concern or not, both fall into Category III. This is reasonable because these projects led to induced seismicity at the initial reservoir stimulation or injectivity test. They are both located close to relatively large cities with substantial industrial activity, critical infrastructure, or heritage sites. Social concern increases the overall GRID score for St. Gallen more as compared to Basel, especially due to increased concern in the public after an induced earthquake in Basel. The Riehen project, although without inducing felt seismicity, falls into Category II. This is meaningful because the project is located close to in a densely-populated area with moderate natural seismicity. However, the shallow depth, sedimentary rock, and relatively low volumes in the project mean that induced seismicity is rather unlikely. If a Basel-type project was situated in a lowrisk area, such a project would fall into Category II, since negative consequences to the population, structures, or the wider economy would be unlikely. However, if social concern was high, even in a population outside the affected area, the project would qualify as Category III. 

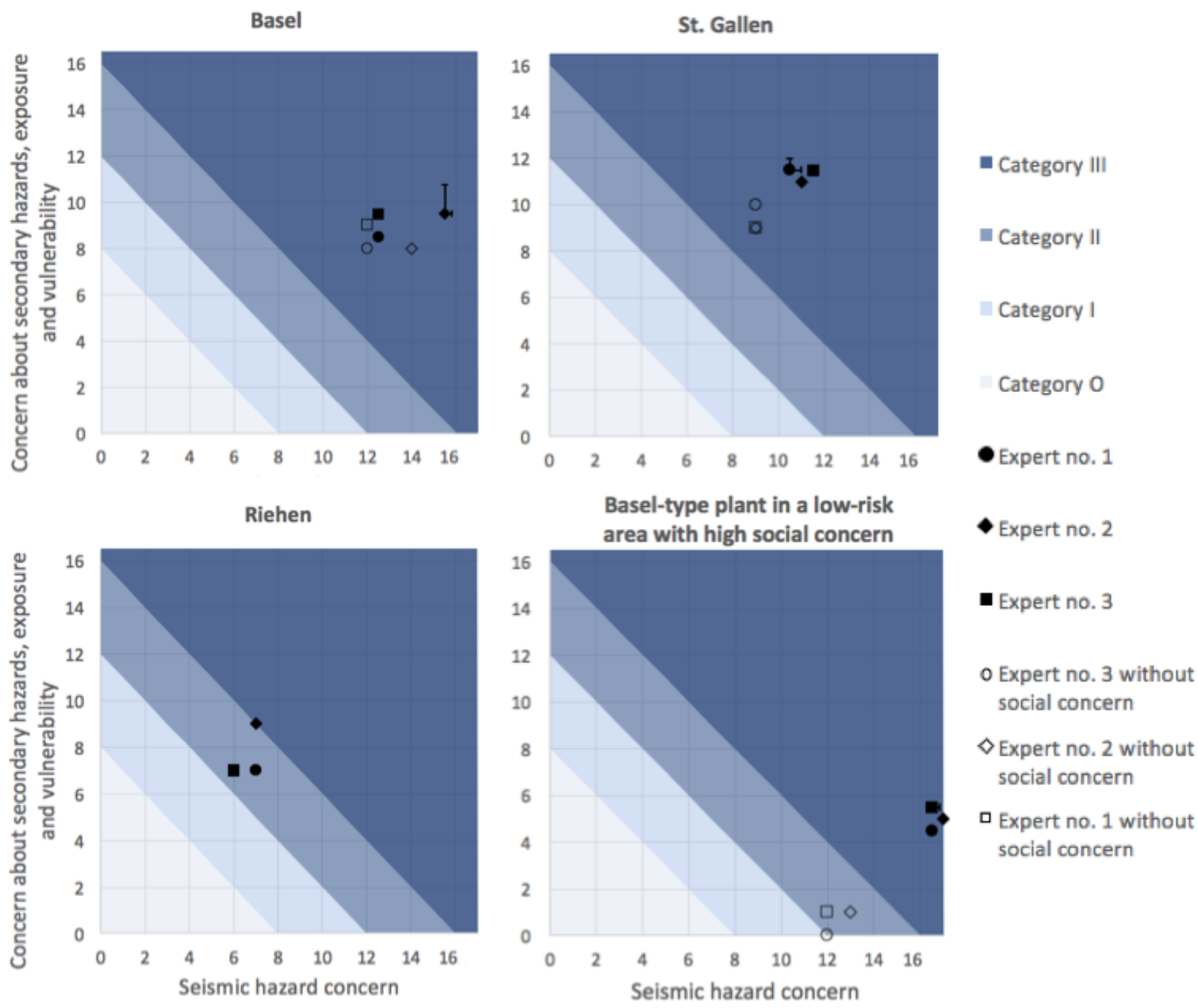

Figure 3. GRID scores for four geothermal projects. Note: When social concern is rated as zero, then scores with and without social concern overlap and are not visible in the graph.

\section{Risk governance framework for induced seismicity of geothermal projects}

In this section, a framework for choosing tailor-made risk governance measures of induced seismicity for the different GRID category projects is described.

\subsection{Definition of risk governance}

We chose the concept of "risk governance" because it is defined as "the totality of actors, rules, conventions, processes, and mechanisms concerned with how relevant risk information is collected, analyzed, and communicated and how management decisions are taken" [p. 80, 62]. Also named as a shift "from government to governance" [63, 64], this concept assumes that risk is dealt with and influenced by multiple actors, including geothermal energy project operators, licensing authorities/regulators, experts (including those in academia), stakeholders, media, and the wider public. The risk governance concept acknowledges two dimensions: (i) the 'factual' risk dimension addressed in technical risk assessments and (ii) the value-laden risk dimension, when the perspectives and actions of the decision makers, stakeholders, and the wider public also shape which risks are addressed and whether they are acceptable $[38,42,62,65]$. Risk governance is neither a 
complementary nor a competing concept to risk assessment, risk management, prescriptive 550 and performance-based risk regulation, or legal and compliance procedures of licensing. Risk 551 governance, in fact, includes all these elements and adds wider consideration of social concern assessment, information (outreach), and public and stakeholder engagement [62].

\subsection{Tailor-made risk governance}

Our proposed framework combines three elements: complete project life cycle, a socio-technical approach, and case dependence. The complete project life cycle perspective is adopted because induced seismicity requires measures from the initial exploration stage to the end of the project and beyond. Induced seismicity can occur decades after the initial stimulation or the end of operation [10]. The socio-technical approach is used because induced seismicity is a complex risk that requires combining technical elements (such as hazard and risk assessment or seismic monitoring) with stakeholder and public engagement to address social concerns. Case dependence helps distinguish which projects require which types and levels of risk governance. In some projects, risk governance can be very simple, involving few actors and largely limited to empirical hazard assessment. In other contexts, it can require much more involvement.

The proposed framework describes good-practice approaches to governing induced seismicity and does not intend to make recommendations for regulatory restrictions. The framework concentrates on governing induced seismicity risk on a project-by-project basis rather than on a national-level governance and regulatory processes. Such a focus is adequate because geothermal-induced seismicity is a new, rather than a widespread, phenomenon. In every project, the operator, through interaction with the regulators, stakeholders, and the public, can decide to: (i) go ahead with the project and take the induced seismicity risk, keeping it as low as possible and below the limits prescribed by regulation, (ii) transfer parts of the risk to insurance, or (iii) terminate the project because of intolerable risk.

The selection of tailor-made risk governance measures for each GRID category is shown in Table 4. These risk governance measures are discussed in Sections 5.3-5.11. Figures 4, 5 and 6 present the risk governance measures for GRID Categories I, II, and III. These figures also include the key actors participating in the process. The risk governance framework in this paper covers the role of four actor groups: (i) project operators, (ii) licensing authorities and/or regulators, (iii) independent experts, and (iv) stakeholder groups and the general public. There are also other actors involved. For example, there are (re)insurance companies or construction companies, but these actors are not explicitly shown in the figures, due to their relevance to a specific measure only.

587 Table 4. Summary of tailor-made risk governance measures for four GRID categories

\begin{tabular}{|l|l|l|l|l|}
\hline & Category $\mathbf{0}$ & Category I & Category II & Category III \\
\hline $\begin{array}{l}\text { Initial hazard and } \\
\text { risk assessment }\end{array}$ & none & $\begin{array}{l}\text { empirical, scenario- } \\
\text { based hazard } \\
\text { assessment }\end{array}$ & $\begin{array}{l}\text { empirical, scenario- } \\
\text { based hazard and risk } \\
\text { assessment }\end{array}$ & $\begin{array}{l}\text { probabilistic hazard and } \\
\text { risk assessment }\end{array}$ \\
\hline $\begin{array}{l}\text { Social site } \\
\text { characterization }\end{array}$ & none & voluntary & necessary & necessary \\
\hline $\begin{array}{l}\text { Information and } \\
\text { outreach on } \\
\text { induced seismicity }\end{array}$ & none & necessary & necessary & necessary \\
\hline $\begin{array}{l}\text { Two-way } \\
\text { engagement }\end{array}$ & none & voluntary & necessary & necessary \\
\hline Insurance and & none & necessary & necessary & necessary \\
\hline
\end{tabular}


588

\begin{tabular}{|l|l|l|l|l|}
\hline liability & & & & \\
\hline $\begin{array}{l}\text { Structural } \\
\text { retrofitting }\end{array}$ & none & optional & optional & necessary to consider \\
\hline Seismic monitoring & none & single station & seismic network & seismic network \\
\hline Traffic light system & none & $\begin{array}{l}\text { voluntary magnitude- } \\
\text { based }\end{array}$ & magnitude-based & $\begin{array}{l}\text { adaptive, in parallel to } \\
\text { magnitude-based }\end{array}$ \\
\hline
\end{tabular}

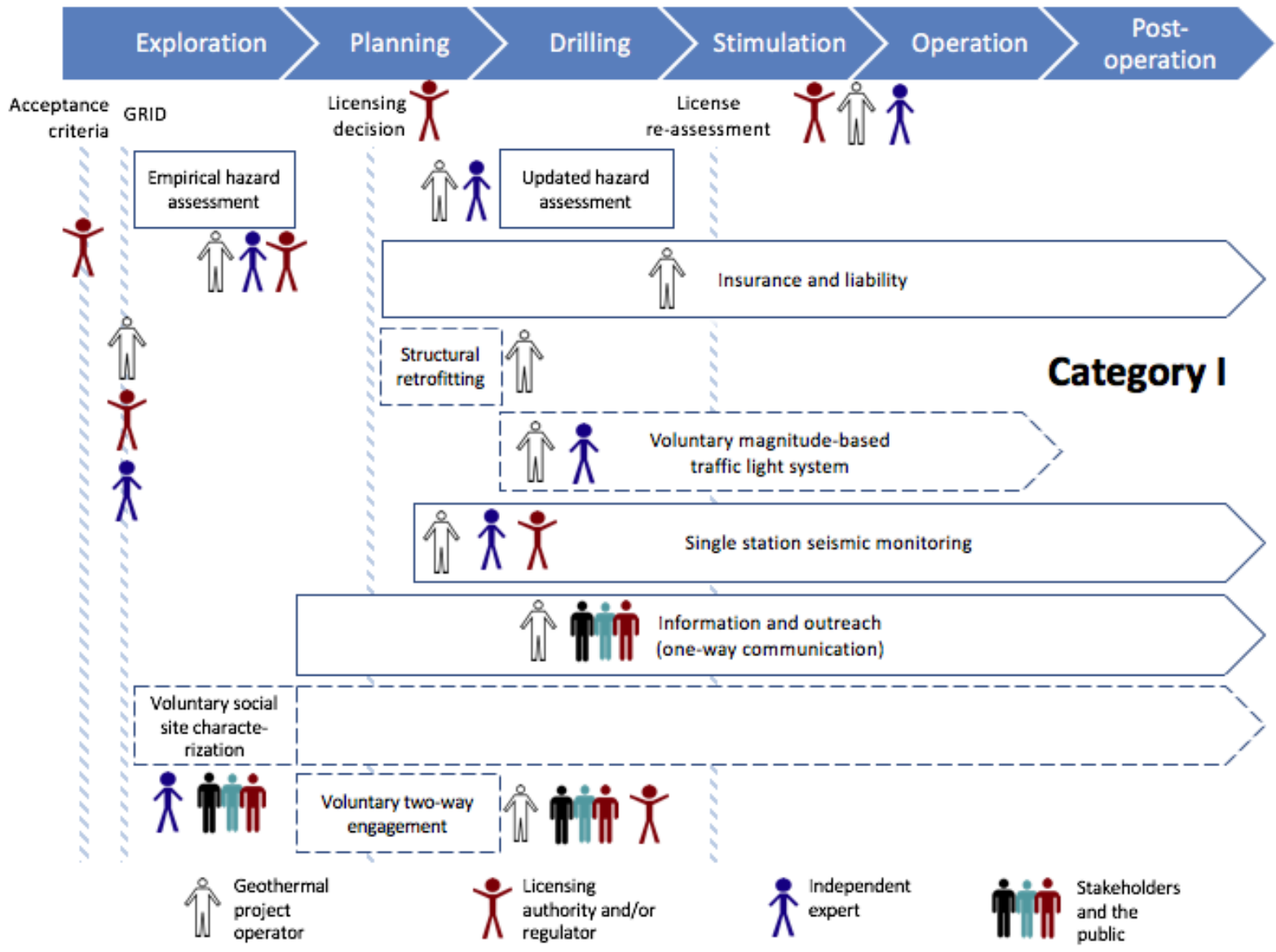

Figure 4. Risk governance measures for GRID Category I projects 


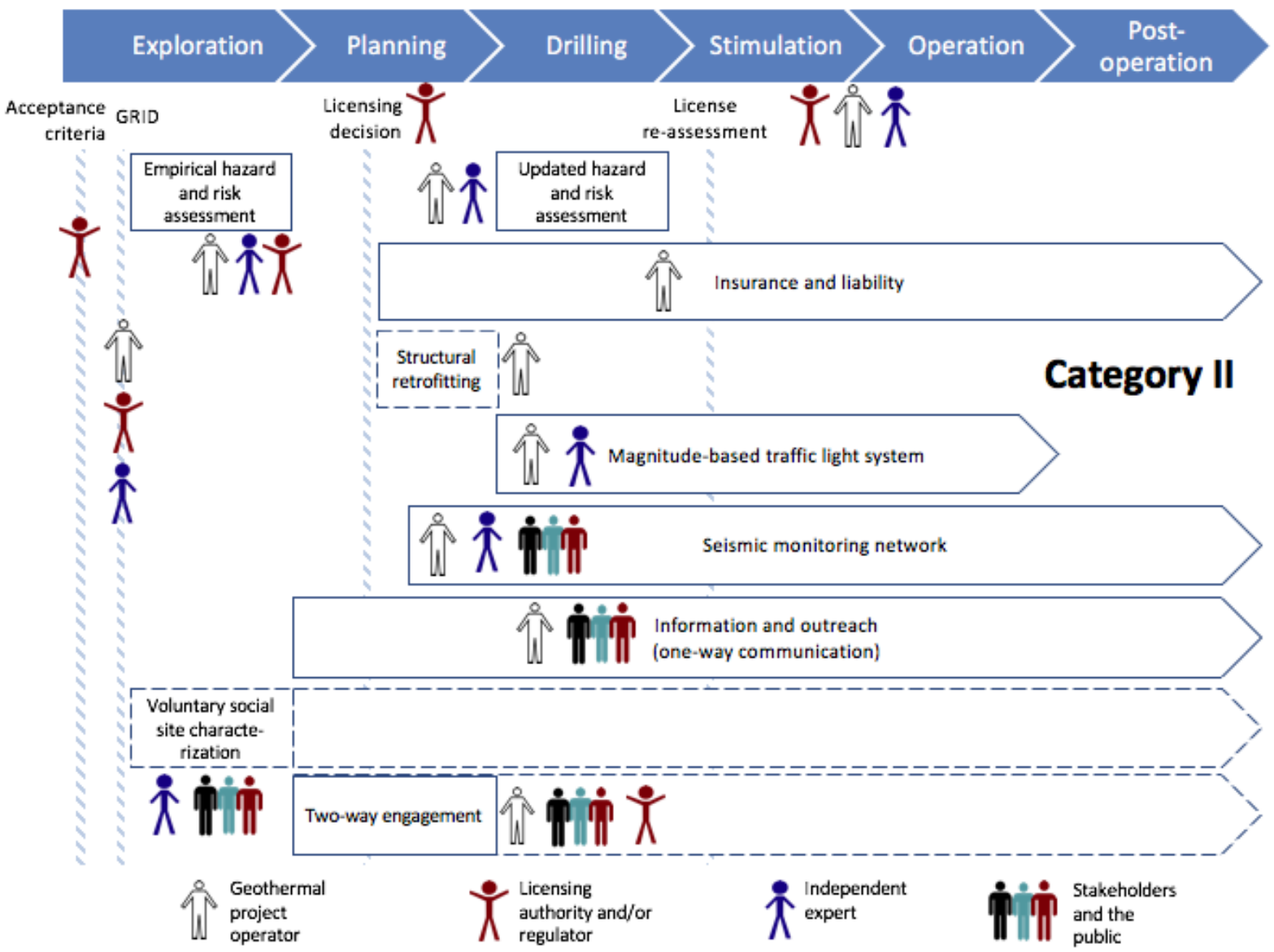

Figure 5. Risk governance measures for GRID Category II projects

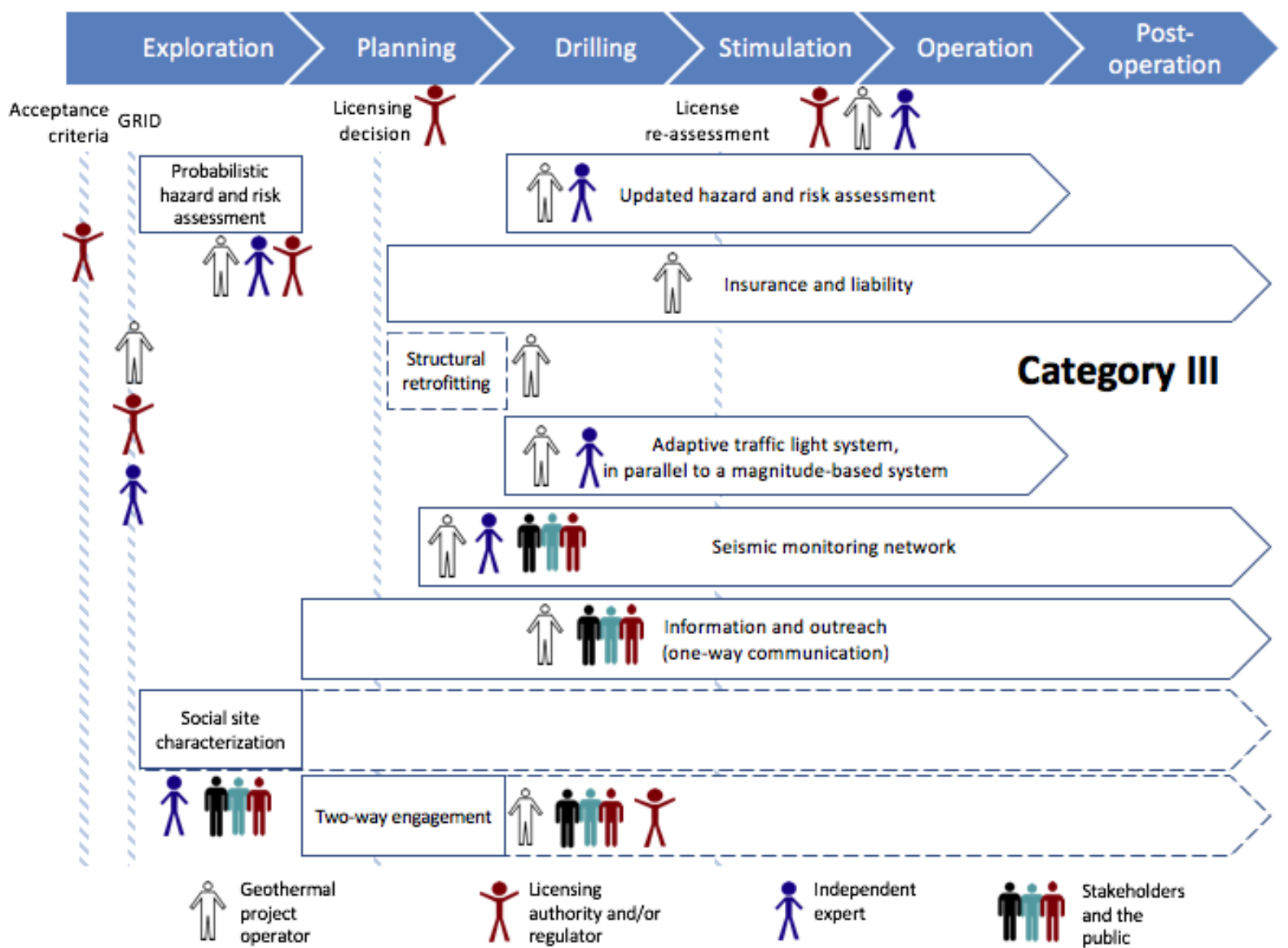

Figure 6. Risk governance measures for GRID Category III projects 
The proposed risk governance framework, like other frameworks in Section 3.2, is meant as a list of good-practice recommendations. To some extent, the framework also 600 considers the potential role of regulations. In the absence of Swiss regulations specific to

601

602

603

604

605

606

607

608

609

610

611

612

613

614

615

616

617

618

619

620

621

622

623

624

625

626

627

628

629

630

631

632

633

634

635

636

637

638

639

640

641

642

643

644

645 geothermal induced seismicity (Section 3.1), and given the current ambition for substantial geothermal deployment in Switzerland [66], a parallel process is important to develop the regulatory framework. For new risks that are dealt with on project-by-project basis, performance-based regulation is generally recommended [67]. In contrast to prescriptive regulations that defines exact limits, thresholds, and processes for risk mitigation, performance-based regulations set performance goals. Such regulations allow flexibility for the operators in balancing risk, costs, benefits, and finding innovative solutions to achieve the agreed goals. Prescriptive regulations, however, explicitly require that the operators monitor the risk and meet the given thresholds. A hybrid approach that combines elements of performance-based and prescriptive regulation could be suited to the management of induced seismicity by geothermal projects in Switzerland. Like with other induced seismicity regulation examples worldwide (Section 3.1), authorities could define a combination of prescriptive thresholds and performance-based goals in terms of injection parameters, risk metrics, or monitoring, management, and reporting measures.

In the recommended risk governance process, at the very start of the risk governance process, acceptable risk criteria or thresholds are defined prescriptively by the licensing authority, possibly with input from the other actors. The outcomes of the risk assessment and the proposed plan of risk mitigation and management would be checked against these thresholds during the process of issuing the licensing permit. The definition of such acceptable thresholds is intrinsically a value-laden matter [40]. This decision is often embedded in the regulatory framework that already exists in a specific country, e.g. [68]. In Switzerland, the current Ordinance of Protection against Major Accidents [69], which is frequently applied in the chemical industry, has also been used as guidance for induced seismicity [21]. The ordinance reaches as low annualized probabilities as low as $10^{-7}$ or $10^{-11}$. Extrapolating seismic hazard and risk assessment to such low probabilities is problematic. Therefore, there is a need in Switzerland to develop an ordinance that specifically addresses the risk acceptance criteria for induced seismicity. The Swiss Seismological Service has recently proposed such thresholds, which are now being discussed among various stakeholders.

After the drilling and initial stimulation, more data become available and the initial hazard and risk assessment should be updated. The assumptions made in the assessment should be systematically checked against new observations in order to ensure that the predefined acceptance criteria are not exceeded. It is recommend that the licensing authority be responsible for conducting the license re-assessment task using the criteria and processes and at a frequency specified in the licensing decision.

\subsection{Initial hazard and risk assessment}

Induced seismicity hazard and risk assessment is typically the basis for licensing decisions, design, and implementation of risk monitoring and management, as well as for communication with stakeholder groups and the public. Depending on the project, several studies, such as seismic surveys, resource exploration, or a building inventory assessment, may have been conducted before the actual hazard and risk assessment. Ideally, seismicity has been covered as one factor in these studies, which serve as a starting point for hazard and risk assessment. 
The higher the GRID category, the more thorough the hazard and risk assessment should be. Our recommendations are:

- Category 0: Since the concern about induced seismicity is low or absent, no dedicated induced seismicity hazard or risk assessment is required.

- Category I: As induced seismicity may be expected, even if damaging events are unlikely, induced seismicity hazard assessment should be conducted as part of the environmental impact assessment. A seismic hazard assessment, based on analogues, empirical data, and scenario calculations, is sufficient. The key uncertainties should be mentioned in order to decide, during the review process, whether additional uncertainty analysis is warranted. This assessment should analyze the natural seismicity in a $10 \mathrm{~km}$ radius from the project site, quantify the stress changes in the well's vicinity, and assess the annual probability of an induced event of $M_{L} \geq 2$. If this annual probability exceeds $1 \%$, we suggest that such projects would be moved to GRID Category II.

665

666

667

668

669

670

671

672

673

674

675

676

677

678

679

680

681

682

683

684

685

686

687

688

689

690

691

692

693

694 those buildings and infrastructure, if any, that are considered especially vulnerable to low magnitude events, such as heritage masonry structures or Class II and Class III structures [44]. Such risk assessment could be based on analogues, empirical data and scenario calculations. Sources of key uncertainties should be mentioned in order to help decide, during the review process, whether in-depth analysis in needed.

- Category II: For Category II projects, induced seismicity hazard and risk should also be assessed as part of the environmental impact assessment. In addition to the empirical, scenario-based hazard assessment, recommended for Category I projects, uncertainties should be explicitly quantified, accounting for alternative models and mechanisms. Scenario calculations should cover both expected induced seismicity and ground shaking impacts. The worst-case scenario should be quantified, too, such as the magnitude of a two-sigma event with an annualized probability below $5 \%$ and its impacts. If the annual probability of $M_{L} \geq 3$ exceeds $1 \%$, such projects should be moved to GRID Category III. The assessment should already cover the measures of seismic monitoring, traffic light system, and emergency procedures.

Like for Category I, risk assessment should be conducted only for those structures or infrastructures, if any, in Class II and III, and vulnerable heritage sites [44].

- Category III: Since induced seismicity is likely, and damaging events cannot be excluded, a dedicated study of induced seismicity hazard and risk assessment is recommended. Such a study should include a detailed risk assessment in terms of financial losses and personal risk. Analytical probabilistic risk assessment of the specific building and infrastructure items is preferable to empirical approaches. It is thus recommended to characterize seismic hazard using Ground Motion Prediction Equations [24] instead of macroseismic intensity [70].

This hazard and risk assessment should be fully probabilistic. Logic-tree analysis could be used to explicitly account for both aleatory and epistemic uncertainties [60]. Seismicity forecasting models should consider the expected hydraulic footprint of the stimulation and be coupled to one or several geo-mechanical models [15]. A strategy for calibration and validation of the hazard and risk model, once the drilling has been completed, should be defined. An injectivity test with limited volumes to calibrate the seismic response and ground motion prediction models could be conducted. Low-probability, high-consequence events should be evaluated. The planned measures of structural retrofitting, seismic monitoring, and traffic light systems should be assessed. Emergency procedures should be delineated. 
We suggest that licensing authorities request project operators to conduct this hazard and risk assessment if a project belongs to GRID Category I or higher. The operator could commission an external consultant. The licensing authority would then review it together with an independent expert. In the case of Category III projects, we recommend that a participatory review that involves multiple independent experts be set up [71].

701

702

703

704

705

706

707

708

709

710

\subsection{Social site characterization}

The technical design of induced seismicity hazard and risk management is informed by the initial hazard and risk assessment (Section 5.3). An equivalent type of assessment, called social site characterization, is proposed for informing non-technical activities, such as outreach or public engagement. Social site characterization helps in understanding the awareness, views, experiences, and concerns of the key stakeholders and the public, in order to diagnose key problematic issues to be addressed. Every project developer learns about the region at the initial stages of the project, but social site characterization is seen as a systematic and in-depth effort. It includes such elements as stakeholder mapping, sociopolitical context analysis, semi-structured interviews, or focus groups with the affected population and stakeholders, and media and document analysis. There are several guidelines for conducting such social site characterizations in general [72, 73], and for geothermal projects specifically $[31,74,75]$.

Social site characterization is especially valuable at the early stages of exploration and planning before decisions to build are made. However, it represents only a snapshot of the public and stakeholder views at the time. These views may change quickly, especially if a felt or even damaging event occurs. Social site characterization efforts, therefore, should be iteratively repeated.

These types of social site characterization are recommended for the GRID categories:

- Category 0: Since induced seismicity is low or absent, social site characterization is not necessary.

- Category I: As induced seismicity may be expected, even if damaging events are unlikely, social site characterization can be conducted on a voluntary basis. In addition to concerns about induced seismicity, such characterizations are useful to reveal other problematic issues in the eyes of the stakeholders and the public, e.g., noise or trust in the project operator.

- Category II: Induced seismicity and associated risk and social concerns are possible, thus social site characterizations are useful, although still voluntary. If any two-way engagement or extensive information and outreach measures are planned (Sections 5.5-5.6), such social site characterizations help tailoring these measures to the specific context.

- Category III: Since induced seismicity is likely, and damaging events cannot be excluded, social site characterization is mandatory. It does not only give an indication of any critical issues that may lead to strong societal pushback, but also enables the design of outreach and public engagement programs.

We suggest that the commissioning of such a study is the responsibility of project operators, who may do it for their own purposes, but studies could also be requested by the licensing authority, especially for Category III projects. Involving external experts or experienced consultants is recommended in order to achieve valid and reliable social site characterization outcomes [76]. 


\subsection{Information and outreach on induced seismicity}

746

Information and outreach include all means to provide those who are involved, affected, interested or observing up-to-date status reports of the project and induced seismicity. Information and outreach here are defined as one-way communication from the project operator to the stakeholders and the public. In other sources, such a one-way process is also called communication or engagement, e.g. [24, 34], but it should not be confused with two-way communication or reverse communication, described in Section 5.6.

The higher the seismic hazard, risk, and social concern, the more extensive the information and outreach on induced seismicity should be. The recommendations for the GRID categories are:

- Category 0: Since the concern about induced seismicity is low or absent, information and outreach dedicated to induced seismicity is not necessary.

- Category I: As induced seismicity may be expected, even if damaging events are unlikely, information and outreach are essential from the start of planning onwards, especially if any felt seismicity occurs.

- Category II: Induced seismicity and associated social concerns are possible, thus extensive information and outreach are necessary. As one element, the seismic monitoring outcomes (earthquake locations, magnitudes, and real-time waveforms) could be published in real time on a dedicated website to be accessible by the interested parties at any time. Alert thresholds must be defined and distributed in a timely fashion to relevant parties (civil defense organizations and police stations, etc.).

- Category III: Since induced seismicity is likely, and damaging events cannot be excluded, extensive information and outreach are essential. Along with the Category Il actions, low-probability, high-consequence events should be explicitly commented on. In addition to a website with seismic monitoring outcomes like for Category II, seismicity forecasts could also be published on the website. For example, forecasts for the next 24 hours or seven days could be published. Such forecasts are part of the adaptive traffic light system (Section 5.11). Alerts thresholds must be defined and must be distributed in a timely fashion to relevant parties (civil defense organization and police stations, etc.).

We suggest that project operators, who may or may not involve external experts, should undertake such information and outreach efforts on induced seismicity. For GRID Category III, the licensing authority could mandate that project operators conduct information and outreach activities. Involving an independent agency in seismic monitoring is recommended, since it adds to the transparency of the project and ensures the quality of the assessment.

\subsection{Two-way engagement on induced seismicity}

Two-way engagement is the means to enable those who will be affected or have a stake in becoming involved in the risk governance process. In the case of complex risk issues characterized by large uncertainties and potential pushbacks, two-way engagement is recommended [38, 40-42]. The underlying argument is that controversies-despite increasingly richer and better communicated scientific knowledge-are not solved by science or technical analysis alone and may remain controversial for a very long time [77]. It 
is recommended that the public and stakeholders be involved directly, rather than acting independently by forming interest groups, demonstrating, or lobbying [38, 40, 78]. In the case of geothermal projects in Germany, Wallquist and Holenstein [56, 74] observed that the members of the public near geothermal sites had asked for a fair and open decision-making process in which they could be involved.

There are several guidelines detailing how such engagement could be organized [78, 79]. Two-way engagement is especially valuable at an early exploration and planning stage before decisions to build a plant are made. Engagement may also be needed later on, especially if a felt or even damaging event occurs.

802

There are three general types of two-way engagement [78, 80]:

803

804

805

806

807

808

809

810

811

812

813

814

815

816

817

818

819

820

821

822

823

824

825

826

827

828

829

830

831

832

833

834

835

836

837

838

839

840

- Consultation, like information (Section 5.5), is also a type of one-way communication, but in the reverse direction, from the public and stakeholders to technical risk analysts, project operators, or authorities. Examples of consultation are public or stakeholder meetings and roundtables, when members of the affected public are consulted for their views, but without a binding commitment.

- Collaboration is two-way communication between the technical risk analysts, project operators, and authorities on the one hand and the public and stakeholders on the other hand. Collaboration requires a commitment from both sides. Citizen juries, citizen advisory committees, panels, and public consensus conferences are examples of collaboration.

- Empowerment is the process whereby the public is given the authority to make decisions on the basis of the available evidence and processes. Although rare, an example of such empowerment is a public vote.

The higher the GRID category, the more effort should be dedicated to two-way engagement:

- Category 0: Since the concern about induced seismicity is low or absent, no two-way engagement focused on induced seismicity.

- Category I: As induced seismicity may be expected, even if damaging events are unlikely, two-way engagement is voluntary. If social site characterization indicates signals of potential societal concern (i.e. any of the social concern indicators are rated as 2), such engagement is recommended. Examples of two-way engagement measures are collecting public concerns and openly addressing them on relevant websites, face-to-face interactions between the public and experts, or guided site visits.

- Category II: Induced seismicity and associated concerns are possible and thus twoway engagement should be conducted. In addition to the measures recommended for Category I, examples of more intense measures are: public discussions with external experts who have diverging opinions, public collection of issues to be addressed in risk assessment, or provision of funding to the community to hire its own independent experts.

- Category III: Since induced seismicity is likely, and damaging events cannot be excluded, two-way engagement is necessary (see Category II for measures).

Both project operators and licensing authorities can organize various two-way engagement activities, with or without the help of external experts. For GRID Category III, we suggest that the licensing authority could mandate that the project operators conduct two-way engagement.

841 


\subsection{Insurance and liability}

843

844

845

846

847

848

849

850

851

852

853

854

855

856

857

858

859

860

861

862

863

864

865

866

867

868

869

870

871

872

873

874

875

876

877

878

879

880

881

882

883

884

885

886

887

888

889

890

Insurance for compensating parties for damages due to induced seismicity should be included in the overall accident and environmental impacts insurance of project operators. However, the extent to which risks could be transferred to insurance, instead of investing in reducing risks or deciding not to go on with a project, needs to be defined as part of the licensing procedure. In order to enable fair insurance compensation, a procedure needs to be designed to document damages. Differentiating between the GRID categories, these are the recommendations for insurance and liability considerations are as follows:

- Category 0: Since the concern about induced seismicity is low or absent, no insurance dedicated to induced seismicity is needed.

- Categories I and II: As induced seismicity can be expected to cause only minor damages, insurance policies for induced seismicity and procedures to link these damages with an induced event are necessary. Before the bore hole stimulation, the state of buildings and infrastructure items in Class III should be documented [31]. Building monitoring should be applied to selected buildings with higher damage concerns, such as heritage or Class III buildings.

- Category III: Since induced seismicity is likely, and damaging events are possible, in addition to the insurance of GRID Categories I and II above, a mechanism to monitor the shaking of selected buildings and infrastructure items as a means to clarify the liability should be organized. Documentation of the state of buildings, as well as building monitoring, should be done for Class II and III buildings. A denser building monitoring network, including Class I buildings, with the engagement of the population, is recommended. As a detailed documentation of the state of buildings can be expensive and face privacy issues, voluntary documentation by building owners through crowdsourcing could be set up [81].

Project operators would insure themselves from their own resources for the coverage of induced seismicity damage to the exposed buildings and populations. We suggest that the assessment of this policy, including which share of the risk can be, in principle, transferred to insurance, would be part of the licensing decision, including a transparent communication with the stakeholders and the general public. In addition to the operator's insurance and building monitoring instruments, any other parties may also purchase additional insurance or install their own monitoring instruments.

\subsection{Structural retrofitting}

Structural retrofitting of vulnerable building and infrastructure items is the means to reduce the risk posed to by these structures to the population and the economic well-being around a geothermal site. Structural retrofitting can also be seen as a means to comply with the acceptable risk criterion and can be seen as a good-will action and contribution to the community as protection against natural earthquakes, too. Since it is a relatively costly measure that also causes inconvenience to building owners, investment into retrofitting should be weighed against the benefits [24]. These measures for the GRID categories are recommended:

- Category 0: Since the concern about induced seismicity is low or absent, structural retrofitting is not necessary.

- Category I and II: As induced seismicity may be expected, even if structurally damaging events are unlikely, structural retrofitting should be considered as part of 
hazard and risk assessment (Section 5.3) for vulnerable heritage buildings or those in Class III, if any.

- Category III: Since induced seismicity is likely, and damaging events cannot be excluded, a list of the buildings and infrastructure in the region of interest that need a seismic retrofit should be produced and the retrofitting options analyzed as part of the hazard and risk assessment.

900

901

902

903

904

905

906

907

908

909

910

911

912

913

914

915

916

917

918

919

920

921

922

923

924

925

926

927

928

929

930

931

932

933

934

935

936

937

938

939

\subsection{Seismic monitoring}

Seismic monitoring is a means of establishing the natural seismicity baseline, collecting and preserving evidence of induced seismicity, and enabling the operation of the traffic light system (Section 5.11). The seismic monitoring guidelines are as follows:

- Category 0: Since the concern about induced seismicity is low or absent, no seismic monitoring is necessary.

- Category I: As induced seismicity may be expected, even if damaging events are unlikely, monitoring should enable the detection of microseismicity and felt earthquakes. A single seismic station, not more than 1.5 times the operation depth away, should be installed for a continuous record of event counts. Rough estimates of distance to the station are possible with such a station.

The station should start operating at least three months prior to stimulation in order to establish a background record of seismicity. It needs to run until the end of the operation, including a six-month post-operation phase.

- Category II: As induced seismicity and associated risk and social concerns are considered possible, seismic monitoring should enable the detection of felt earthquakes and their location, as well as enable the functioning of the magnitudebased traffic light system (Section 5.11). A seismic network of at least four continuously recording stations must be placed around the site with one station in the center. The aim is to achieve a complete detection of $M_{L} \geq 1$. The distance to the expected source should be about two times the planned geothermal operation depth, but less than $10 \mathrm{~km}$. The central station should also be equipped with an accelerometer to allow recording of strong motions up to $1 \mathrm{~g}$. A notification and alarm system should be set up to provide real-time information to the operator and regulator about automatically detected and located earthquakes.

The monitoring should start at least six months before the drilling. As induced seismicity can occur after an earthquake-free operation, the network needs to operate for at least six months after the end of an operation, demonstrating that no events are occurring.

- Category III: Since induced seismicity is likely, and damaging events cannot be excluded, a seismic monitoring network as described in Category II should be installed. The aim is to achieve a complete detection of $M_{L} \geq 0.5$ with automatic detection algorithms. In addition to the accelerometer of the central station, multiple accelerometers could be installed, especially in areas with higher damage concerns, such as heritage or Class III buildings. The network needs to start at least six months before drilling and continue, without reducing the number of stations, after the end of operations until the seismicity returns to pre-stimulation levels. 
We suggest that setting up seismic monitoring, especially in addition to the existing

\subsection{Traffic light system} national monitoring network, is the responsibility of the project operator together with the operator of the national network. The notification and alarm system, however, could inform both the project operator and the regulator. For GRID Categories II and III, it is recommended that the documented seismicity be put online to guarantee transparent access by any interested party (Section 5.5).

The traffic light system [35, 82, 83] is a means to manage induced seismicity by determining in real time whether seismicity or associated risks have reached particular levels, indicated as green, yellow, orange, and red, and require geothermal operations to be modified or stopped. Reducing injection or depletion rates, or potentially interrupting operations, leads to a reduction of seismicity with time, but the delay can range from hours to weeks. The commitment to operate a traffic light system will also reduce the overall hazard and risk of the project assessed in the licensing stage, depending on the level of conservatism chosen in the thresholds. The lights can also return to green or yellow after some time, indicating when operations can be restarted.

These types of traffic light systems are recommended for the GRID categories:

- Category 0: Since the concern about induced seismicity is low or absent, no traffic light system is required.

- Category I: As induced seismicity may be expected, even if damaging events are unlikely, voluntary magnitude-based traffic light system, described in Category II, could be installed.

- Category II: As induced seismicity and associated concerns are considered possible, thus a conventional magnitude-based traffic light system should be implemented and coupled to a list of mitigation actions. As described in a variety of studies $[35,82,83]$ and Figure 7, such a system steers the operation to continue as planned (green), continue without increasing (yellow), stop (orange), or release fluids out of the well (red) on the basis of observed local magnitude and peak ground velocity.

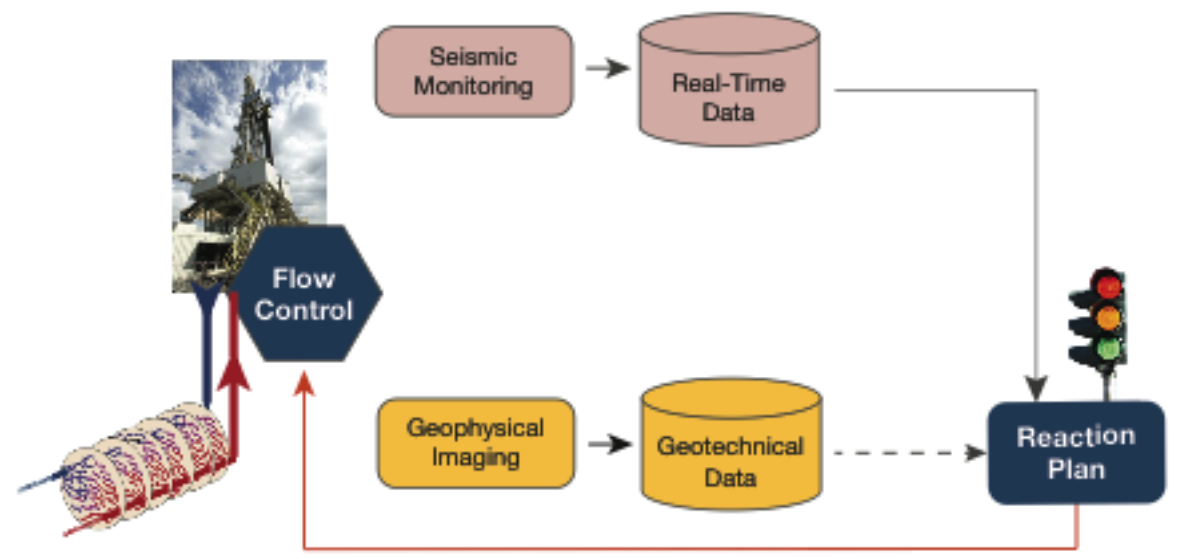

Figure 7. Conventional magnitude-based traffic light system; redrawn from [15].

- Category III: Since induced seismicity is likely and damaging events cannot be excluded, in parallel to the conventional magnitude-based traffic light system, an adaptive traffic light system should be installed as well (Figure 8). Such a system has four additional elements as compared to the conventional one: it is forward looking, probabilistic, adaptive, and based on risk rather than hazard [15, 84]. Forward- 
looking models are used to make probabilistic forecasts of expected future seismicity based on parameters, such as current seismicity, current and planned pressures, and other factors. The actions in such a system are not determined reactively after an event of a certain magnitude occurs, but the system can anticipate an event's magnitude in advance. The most advanced systems are envisioned to jointly optimize seismicity and reservoir creation [46]. Probabilistic forecasts are made, accounting for epistemic and aleatory uncertainties in models. The term "adaptive" means that hazard and risk calculation is updated automatically, when new data become available and when a suite of forecasting models is tested to find the model that performs best [19]. Risk-based traffic light systems mean that forecasting and initiation of mitigation actions depends not only on the forecasted hazard (magnitudes or ground shaking). Rather, a building stock model is used to conduct automatic risk calculations and enable a risk-based initiation of actions.

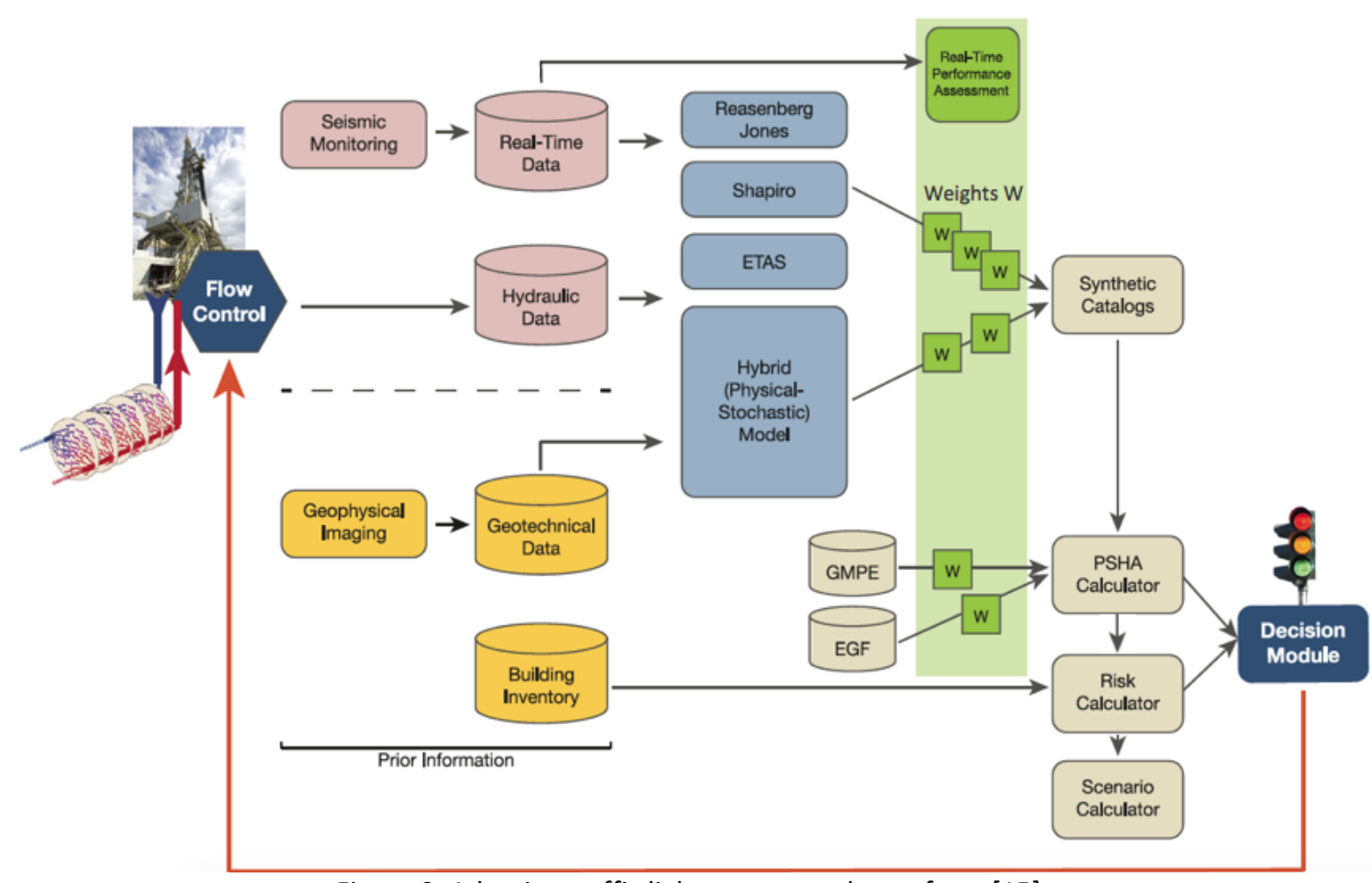

Figure 8. Adaptive traffic light system; redrawn from [15].

We suggest that setting up and operating such traffic light systems are the responsibilities of project operators, who may also involve external consultants. Defining the thresholds for action is a value-laden decision, based on the acceptable risk thresholds and, thus, should be addressed by the licensing authority as part of the licensing process (Section 5.2). We recommend that, for Category III, a panel of independent experts should be formed so that it can be called to convene quickly, if anything unexpected occurs. The role of this panel would be to give advice to the project operator and regulator on further plant operations, risk mitigation, and other necessary actions to keep seismicity risk at acceptable levels.

\section{Discussion and outlook}

This paper proposes the Geothermal Risk of Induced seismicity Diagnosis (GRID) as a method of categorizing geothermal energy projects at early planning stages in terms of 
1010 induced seismicity hazard, risk (exposure and vulnerability of the structures and 1011 populations), and social concern. Based on GRID, a framework to choose good-practice and 1012 tailor-made risk governance measures for geothermal-induced seismicity are proposed. Both 1013 contributions are new in terms of their application to geothermal energy and for their socio1014 technical view.

1015 GRID is a transparent, reproducible, and transferable approach, thus assuring 1016 fairness in the sense that all projects are treated equal. It relies on simple indicators that are 1017 based on the current understanding of what determines induced seismicity hazard, risk, and 1018 social concern. Such a simple approach is chosen intentionally to allow conducting GRID at 1019 an early stage of the project, before drilling or communication with the public. GRID scores 1020 are especially valuable in Switzerland, where the Swiss Energy Strategy 2050 [66] envisions a 1021 substantial deployment of deep geothermal plants in the coming decades. The GRID scores 1022 allow any interested company or municipality to conduct a quick initial assessment. A simple 1023 approach is also more accessible to practitioners with varying experience levels on induced 1024 seismicity. Even then, these experts may need to seek professional advice when evaluating 1025 specific GRID indicators. It must be noted that the GRID scores and processes do not replace 1026 in-depth hazard and risk assessment, which still need to be conducted. Such a simple GRID 1027 approach may be susceptible to subjectivity, especially in evaluating social concern. At the 1028 same time, GRID is also promotes transparency and discussion among at least three of the 1029 involved parties. To further minimize subjectivity, we argue for the implementation of a 1030 specific process to follow (Section 4.1).

Given the rapidly evolving scientific understanding of induced seismicity and the lack of existing deep geothermal projects in Switzerland, the proposed GRID scores and underlying indicators need to be updated when new evidence becomes available. The definition of specific GRID indicators, e.g., how to measure industrial and commercial activity or what constitutes low or high concern, should be further refined. New indicators may need to be added. For pilot Enhanced Geothermal Systems that are mostly in GRID Categories II or III, the GRID score will likely require customization and refinement on a project-by-project basis. For generic GRID validation, quantitative simulation of all possible GRID cases and associated seismic hazards and risks could be conducted.

GRID divides all projects into four categories, but does not have a category "do not proceed". While such a category may be useful, for example, in the vicinity of extended active faults [36] or infrastructures with high environmental risk, it is our view that GRID approach shall identify the project as Category III and sensitize the involved parties. The actual decision is left to the project operator and licensing authority, and should be based on in-depth hazard and risk assessment.

The proposed risk governance framework, like other existing induced seismicity frameworks [15, 24, 31, 34, 35], is conceptual. In the absence of geothermal projects with induced seismicity at an advanced phase, this framework has never been applied in full, especially for Category III. Therefore, it cannot yet be illustrated or validated from exploration to post-operation. Since geothermal-induced seismicity is at a relatively early stage of scientific, regulatory, and public understanding, it is likely that every new project will lead to revisions of this framework and it is appropriate that the framework is applied and revised on a project-by-project basis. Upcoming projects in Switzerland will serve as good cases for scrutinizing the framework.

The proposed framework includes three types of evidence: (i) physical assessments based on empirical data and theory-based inferences; (ii) expert judgments in the evaluation of GRID score or expert review panels; and (iii) social data, such as from interviews or focus groups during social site characterization. When done well, all these evidence types, 
1059 including expert elicitations $[85,86]$ or social scientific inquiries [76, 87], can provide valid 1060 and reliable results. Caution, however, must be taken when using the gathered insights for 1061 forecasting purposes. Empirical data, theory-based inferences, and expert judgments on 1062 seismicity or damage can be used in a forward-looking manner, beyond direct evidence. 1063 Findings from social scientific methods are only snapshots of the social situation at that time 1064 and do not provide grounds for predictions [76].

$1065 \quad$ Numerous other relevant aspects currently fall outside GRID and the proposed 1066 framework for risk governance. Induced seismicity risk, for example, is never governed in 1067 isolation from other geothermal energy risks, costs, and benefits. In the future, closer 1068 integration should be aimed for between induced seismicity risk governance and the 1069 considerations of geothermal energy resource availability, produced energy, project costs and financial risks etc. For example, analytic-deliberative Risk-Cost-Benefit-Analysis could be used [40]. The role of national and local regulations has not yet been elaborated in depth, either.

Both GRID and the associated risk governance framework have been customized to the case of Switzerland. They could be rather directly transferred to other areas with a very similar geologic context, buildings, and infrastructures, for example, Alpine and pre-Alpine areas in Western Europe. However, the generic type of the presented approach is adaptable worldwide. While the framework is tailored towards geothermal energy, it can also be

1078

1079 adapted to other types of applications that have the potential for induced seismicity, such as oil and gas extraction, waste water disposal, or $\mathrm{CO}_{2}$ sequestration.

1080

1081

1082

1083

\section{Acknowledgements}

1084

This work has been completed within the Swiss Competence Center on Energy Research 1085 Supply of Electricity, with the support of the Energy Turnaround National Research Programme (NRP70) of the Swiss National Science Foundation. We also acknowledge the funding of the Swiss National Science Foundation Ambizione Energy Grant (Grant number 160563, E.T.), the Swiss Federal Office of Energy and EnergieSchweiz through the project GEOBEST-CH (S.W), and the EU Horizon 2020 Project DESTRESSS (S.W.). We thank Marco Broccardo, Olivier Ejderyan, Domenico Giardini, Toni Kraft, Arnaud Mignan, Michael Stauffacher, and especially Bozidar Stojadinovic for feedback on the first version of this manuscript as well as Julian J. Bommer, Gunter Siddiqi and another anonymous reviewer for

1093 their feedback on the final manuscript.

1095

1096

\section{References}

[1] J.H. Williams, A. DeBenedictis, R. Ghanadan, A. Mahone, J. Moore, W.R. Morrow, S. Price, M.S. Torn, The Technology Path to Deep Greenhouse Gas Emissions Cuts by 2050: The 1098 Pivotal Role of Electricity, Science, 335 (2012) 53-59.

1099 [2] IPCC, Intergovernmental Panel on Climate Change Working Group III Contribution to AR 5 1100 - Mitigation of Climate Change, in, Intergovernmental Panel on Climate Change, -, 2014.

1101 [3] S. Hirschberg, S. Wiemer, P. Burgherr, Energy from the Earth: Deep geothermal as a 1102 resource for the future? TA Swiss Geothermal Project Final Report., in, Paul Scherrer Institute, Villigen, 2014.

1104 [4] R. Bertani, Geothermal power generation in the world 2005-2010 update report, 1105 Geothermics, 41 (2012) 1-29. 
1106 [5] M.W. Hitzman, D.C. Clarke, E. Detournay, J.H. Dieterich, D.K. Dillon, S.J. Green, R.M. 1107 Habiger, R.K. McGuire, J.K. Mitchell, J.E. Shemeta, J.L. Smith, Induced Seismicity Potential in 1108 Energy Technologies, The National Academies Press, Washington DC, 2012.

1109 [6] A. Zang, V. Oye, P. Jousset, N. Deichmann, R. Gritto, A. McGarr, E. Majer, D. Bruhn, 1110 Analysis of induced seismicity in geothermal reservoirs - An overview, Geothermics, 52 1111 (2014) 6-21.

1112 [7] D. Giardini, Geothermal quake risks must be faced, Nature, 462 (2009) 848-849.

1113 [8] T. van Eck, F. Goutbeek, H. Haak, B. Dost, Seismic hazard due to small-magnitude, shallow-source, induced earthquakes in The Netherlands, Engineering Geology, 87 (2006) 105-121.

1116 [9] S.J. Bourne, S.J. Oates, J.J. Bommer, B. Dost, J. van Elk, D. Doornhof, A Monte Carlo Method for Probabilistic Hazard Assessment of Induced Seismicity due to Conventional Natural Gas Production, Bulletin of the Seismological Society of America, 105 (2015) 172111191738.

1120 [10] W.L. Ellsworth, Injection-Induced Earthquakes, Science, 341 (2013).

1121 [11] J.L. Rubinstein, A.B. Mahani, Myths and facts on wastewater injection, hydraulic 1122 fracturing, enhanced oil recovery, and induced seismicity, Seismological Research Letters, 86 1123 (2015) 1060-1067.

1124 [12] S.J. Gibowicz, Chapter 1 - Seismicity Induced by Mining: Recent Research, in: D. Renata 1125 (Ed.) Advances in Geophysics, Elsevier, 2009, pp. 1-53.

1126 [13] M.D. Zoback, S.M. Gorelick, Earthquake triggering and large-scale geologic storage of 1127 carbon dioxide, Proceedings of the National Academy of Sciences, 109 (2012) 10164-10168.

1128 [14] R.J. Pawar, G.S. Bromhal, J.W. Carey, W. Foxall, A. Korre, P.S. Ringrose, O. Tucker, M.N. 1129 Watson, J.A. White, Recent advances in risk assessment and risk management of geologic 1130 CO2 storage, International Journal of Greenhouse Gas Control, 40 (2015) 292-311.

1131 [15] S. Wiemer, T. Kraft, D. Landtwing, Seismic risk, in: S. Hirschberg, S. Wiemer, P. Burgherr 1132 (Eds.) Energy from the Earth: Deep geothermal as a resource for the future? TA Swiss 1133 Geothermal Project Final Report., Paul Scherrer Institute, Villigen, 2014, pp. 263-295.

1134 [16] K.F. Evans, A. Zappone, T. Kraft, N. Deichmann, F. Moia, A survey of the induced seismic 1135 responses to fluid injection in geothermal and $\mathrm{CO} 2$ reservoirs in Europe, Geothermics, 41 1136 (2012) 30-54.

1137 [17] E.L. Majer, R. Baria, M. Stark, S. Oates, J. Bommer, B. Smith, H. Asanuma, Induced 1138 seismicity associated with Enhanced Geothermal Systems, Geothermics, 36 (2007) 185-222.

1139 [18] C.E. Bachmann, S. Wiemer, J. Woessner, S. Hainzl, Statistical analysis of the induced 1140 Basel 2006 earthquake sequence: introducing a probability-based monitoring approach for 1141 Enhanced Geothermal Systems, Geophysical Journal International, 186 (2011) 793-807. 
1142 [19] B. Mena, S. Wiemer, C. Bachmann, Building Robust Models to Forecast the Induced 1143 Seismicity Related to Geothermal Reservoir Enhancement, Bulletin of the Seismological 1144 Society of America, 103 (2013) 383-393.

1145 [20] B. Edwards, T. Kraft, C. Cauzzi, P. Kästli, S. Wiemer, Seismic monitoring and analysis of 1146 deep geothermal projects in St Gallen and Basel, Switzerland, Geophysical Journal 1147 International, 201 (2015) 1020-1037.

1148 [21] S. Baisch, D. Carbon, U. Dannwolf, B. Delacou, M. Devaux, F. Dunand, R. Jung, M. Koller, 1149 C. Martin, M. Sartori, R. Secanell, R. Vörös, Deep Heat Mining Basel - Seismic risk analysis, 1150 Departement für Wirtschaft, Soziales und Umwelt des Kantons Basel-Stadt, Basel, 2009.

1151 [22] S. Muratore, S. Müller, H. Kulla, B. Knüssel, L. Allemann, A. de Martino, N. Meier, N. 1152 Stoudmann, D. Tschan, Tiefengeothermie: Das Project St. Gallen. USYS Transdisziplinäre 1153 Fallstudie 2015., in, USYS Transdisciplinarity Lab, Zurich, 2016.

1154 [23] N. Deichmann, D. Giardini, Earthquakes Induced by the Stimulation of an Enhanced 1155 Geothermal System below Basel (Switzerland), Seismological Research Letters, 80 (2009) 1156 784-798.

1157 [24] J. Bommer, H. Crowley, R. Pinho, A risk-mitigation approach to the management of 1158 induced seismicity, J Seismol, (2015) 1-24.

1159 [25] R.E. Kasperson, O. Renn, P. Slovic, H.S. Brown, J. Emel, R. Goble, J.X. Kasperson, S. 1160 Ratick, The Social Amplification of Risk: A Conceptual Framework, Risk Analysis, 8 (1988) 1161 177-187.

1162 [26] O. Renn, W.J. Burns, J.X. Kasperson, R.E. Kasperson, P. Slovic, The Social Amplification of 1163 Risk: Theoretical Foundations and Empirical Applications, Journal of Social Issues, 48 (1992) 1164 137-160.

1165 [27] Y.E. Saud, K. Israni, J. Goddard, Bow-tie diagrams in downstream hazard identification 1166 and risk assessment, Process Safety Progress, 33 (2014) 26-35.

1167 [28] P. Dumas, M. Serdjuk, R. Kutschick, S. Fraser, GEOELEC Deliverable $n^{\circ} 4.1$. Report on 1168 geothermal regulations., European Commission, Brussels, Belgium 2013.

1169 [29] Ground Water Protection Council and Interstate Oil and Gas Compact Commission, 1170 Potential injection-induced seismicity associated with oil \& gas development: a primer on 1171 technical and regulatory considerations informing risk management and mitigation, 2015.

1172 [30] B.o.L.M. US Department of the Interior, Final programmatic environmental impact 1173 statement for geothermal leasing in the Western United States, in, US Department of the 1174 Interior, Bureau of Land Management,, 2008.

1175 [31] E.L. Majer, J. Nelson, A. Robertson-Tait, J. Savy, I. Wong, Best Practices for Addressing 1176 Induced Seismicity Associated With Enhanced Geothermal Systems (EGS), in, 2013.

1177 [32] Canadian Association of Petroleum Producers, CAPP hydraulic fracturing operating 1178 practice. Anomalous induced seismicity: assessment, monitoring, mitigation and response, 1179 in, CAPP, 2012. 
1180 [33] American Exploration and Production Council, Induced seismicity and the O\&G industry, 1181 in, AXPC, 2013.

1182 [34] E.L. Majer, J. Nelson, A. Robertson-Tait, J. Savy, I. Wong, Protocol for Addressing 1183 Induced Seismicity Associated with Enhanced Geothermal Systems, in, U.S. Department of 1184 Energy, Washington DC, 2012.

1185 [35] R.J. Walters, M.D. Zoback, J.W. Baker, G.C. Beroza, Characterizing and Responding to 1186 Seismic Risk Associated with Earthquakes Potentially Triggered by Fluid Disposal and 1187 Hydraulic Fracturing, Seismological Research Letters, 86 (2015) 1110-1118.

1188 [36] M. Zoback, Managing the seismic risk posed by wastewater disposal Earth magazine, 57 1189 (2012) 38.

1190 [37] E. Hoşgör, J. Apt, B. Fischhoff, Incorporating seismic concerns in site selection for 1191 enhanced geothermal power generation, Journal of Risk Research, 16 (2013) 1021-1036.

1192 [38] P.C. Stern, H.V. Fineberg, Understanding Risk: Informing Decisions in a Democratic 1193 Society, in, The National Academies Press, Wachington DC, 1996.

1194 [39] O. Renn, T. Webler, H. Rakel, P. Dienel, B. Johnson, Public participation in decision 1195 making: A three-step procedure, Policy Sciences, 26 (1993) 189-214.

1196 [40] B. Fischhoff, The realities of risk-cost-benefit analysis, Science, 350 (2015).

1197 [41] IRGC, An introduction to the IRGC Risk Governance Framework, International Risk 1198 Governance Council, Lausanne, 2012.

1199 [42] O. Renn, Risk governance : coping with uncertainty in a complex world, London : 1200 Earthscan, London, 2008.

1201 [43] M.D. Mastrandrea, C.B. Field, T.F. Stocker, O. Edenhofer, K.L. Ebi, D.J. Frame, H. Held, E. 1202 Kriegler, K.J. Mach, P.R. Matschoss, G.-K. Plattner, G.W. Yohe, F.W. Zwiers, Guidance note 1203 for lead authors of the IPCC Fifth Assessment Report on consistent treatment of 1204 uncertainties., in, IPCC, -, 2010.

1205 [44] SIA, SIA 261:2003 Action on structures, Swiss Society of Engineers and Architects, 1206 Zurich, 2003.

1207 [45] A. McGarr, B. Bekins, N. Burkardt, J. Dewey, P. Earle, W. Ellsworth, S. Ge, S. Hickman, A. 1208 Holland, E. Majer, J. Rubinstein, A. Sheehan, Coping with earthquakes induced by fluid 1209 injection, Science, 347 (2015) 830-831.

1210 [46] V.S. Gischig, S. Wiemer, A stochastic model for induced seismicity based on non-linear 1211 pressure diffusion and irreversible permeability enhancement, Geophysical Journal 1212 International, (2013).

1213 [47] UNESCO, Hague Convention for the Protection of Cultural Property in the Event of 1214 Armed Conflict, in, 1954.

1215 [48] J.F. Bird, J.J. Bommer, Earthquake losses due to ground failure, ENGINEERING GEOLOGY, 121675 (2004) 147-179. 
1217 [49] M.A. Nowicki, D.J. Wald, M.W. Hamburger, M. Hearne, E.M. Thompson, Development of 1218 a globally applicable model for near real-time prediction of seismically induced landslides, 1219 Engineering Geology, 173 (2014) 54-65.

1220 [50] J. Zhu, D. Daley, L.G. Baise, E.M. Thompson, D.J. Wald, K.L. Knudsen, A Geospatial 1221 Liquefaction Model for Rapid Response and Loss Estimation, Earthquake Spectra, 31 (2014) 1222 1813-1837.

1223 [51] S. Mousavi, A. Bagchi, V.K.R. Kodur, Review of post-earthquake fire hazard to building 1224 structures, Canadian Journal of Civil Engineering, 35 (2008) 689-698.

1225 [52] K. Kremer, G. Simpson, S. Girardclos, Giant Lake Geneva tsunami in AD 563, Nature 1226

[53] M. Stauffacher, N. Muggli, A. Scolobig, C. Moser, Framing deep geothermal energy in mass media: the case of Switzerland, Technological Forecasting and Social Change, 98 (2015) 60-70.

1230 [54] A.-M. Dowd, N. Boughen, P. Ashworth, S. Carr-Cornish, Geothermal technology in 1231 Australia: Investigating social acceptance, Energy Policy, 39 (2011) 6301-6307.

1233

[55] S. Carr-Cornish, L. Romanach, Differences in Public Perceptions of Geothermal Energy Technology in Australia, Energies, 7 (2014) 1555-1575.

1234 [56] L. Wallquist, M. Holenstein, Engaging the public on geothermal energy, in: World 1235 Geothermal Congress, Melbourne, Australia, 2015.

1236 [57] S. Reith, T. Kölbel, P. Schlagermann, A. Pellizzone, A. Allansdottir, Public acceptance of 1237 geothermal electricity production, GEOELEC, -, 2013.

1238 [58] A. Pellizzone, A. Allansdottir, R. De Franco, G. Muttoni, A. Manzella, Exploring public 1239 1240

1241 [59] N.C. Bronfman, R.B. Jiménez, P.C. Arévalo, L.A. Cifuentes, Understanding social 1242

1243 [60] A. Mignan, D. Landtwing, P. Kästli, B. Mena, S. Wiemer, Induced seismicity risk analysis 1244 of the 2006 Basel, Switzerland, Enhanced Geothermal System project: Influence of 1245 uncertainties on risk mitigation, Geothermics, 53 (2015) 133-146.

1246 [61] I. Moeck, T. Bloch, R. Graf, S. Heuberger, P. Kuhn, H. Naef, M. Sonderegger, S. Uhlig, M. 1247 Wolfgramm, The St. Gallen Project: Development of Fault Controlled Geothermal Systems in 1248 Urban Areas, in: World Geothermal Congress 2015, 19-25 April 2015, Melbourne, Australia, 12492015.

1250 [62] IRGC, Risk governance: Towards an integrative apprach, International Risk Governance 1251 Council, Geneva, 2005.

1252 [63] R.A.W. Rhodes, Understanding governance: policy networks, governance, reflexivity and 1253 accountability, Open University Press, Buckingham, 1997. 
1254 [64] G. Walker, F. Tweed, R. Whittle, A framework for profiling the characteristics of risk 1255 governance in natural hazard contexts, Natural Hazards and Earth System Science, 14 (2014) 1256 155-164.

1257 [65] O. Renn, A Model for an Analytic-Deliberative Process in Risk Management, 1258 Environmental Science \& Technology, 33 (1999) 3049-3055.

1259 [66] Der Schweizerische Bundesrat, Botschaft zum ersten Massnahmenpaket der 1260 Energiestrategie 2050 (Revision des Energierechts) und zur Volksinitiative «Für den 1261 geordneten Ausstieg aus der Atomenergie (Atomausstiegsinitiative)", Der Schweizerische 1262 Bundesrat, Bern, 2013.

1263 [67] C. Coglianese, J. Nash, T. Olmstead, Performance-based regulation: prospects and 1264 limitations in health, safety and environmental protection. John F. Kennedy School of 1265 Government at Harvard University Faculty Research Working Paper RWP02-50, Harvard 1266 University, Cambridge, Massachusetts, 2002.

1267 [68] S.N. Jonkman, P.H.A.J.M. van Gelder, J.K. Vrijling, An overview of quantitative risk 1268 measures for loss of life and economic damage, J. Hazard. Mater., 99 (2003) 1-30.

1269 [69] Swiss Federal Council, Ordonnance sur la protection contre les accidents majeurs 1270 (OPAM), in, 2015.

1271 [70] G. Grünthal, European macroseismis scale 1998, in, European Seismological commision, 1272 Luxembourg, 1998.

1273 [71] U.S. Nuclear Regulation Commission, NUREG-2117. Practical Implementation Guidelines 1274 for SSHAC Level 3 and 4 Hazard Studies, Office of Nuclear Regulatory Research, Washington 1275 DC, 2012.

1276 [72] S. Wade, S. Greenberg, Social site characterization: From concept to application, CSIRO, $1277-, 2011$.

1278 [73] S. Brunsting, M. Pol, J. Mastop, M. Kaiser, R. Zimmer, S. Shackley, L. Mabon, R. Howell, 1279 F. Hepplewhite, R. Loveridge, M. Mazurowski, C. Rybicki, Social Site Characterisation for CO2 1280 Storage Operations to Inform Public Engagement in Poland and Scotland, Energy Procedia, 128137 (2013) 7327-7336.

1282 [74] L. Wallquist, M. Holenstein, Stakeholderanalyse Geothermie: Analyse von Einstellungen 1283 und Wahrnehmungsprozessen in, Stiftung Risiko-Dialog, St. Gallen, 2012.

1284 [75] D. Weber, M. Brian, Öffentlichkeitsarbeit für Geothermieprojekte, Omniprint, 1285 Gundelfingen, 2014.

1286 [76] O. Renn, Stakeholder and Public Involvement in Risk Governance, Int J Disaster Risk Sci, $12876(2015)$ 8-20.

1288 [77] D.W. North, P.C. Stern, T. Webler, P. Field, Public and Stakeholder Participation for 1289 Managing and Reducing the Risks of Shale Gas Development, Environmental Science \& 1290 Technology, 48 (2014) 8388-8396. 
1291 [78] T. Dietz, P.C. Stern, Public participation in environmental assessment and decision 1292 making, National Research Council, Washington DC, 2008.

1293 [79] IRGC, A resource guide for developing and implementing science-based stakeholder 1294 involvement research, policy, strategies, and practices, in, IRGC, Lausanne 2013.

1295 [80] P. Krütli, M. Stauffacher, T. Flüeler, R.W. Scholz, Functional-dynamic public participation 1296 in technological decision-making: Site selection processes of nuclear waste repositories, 1297 Journal of Risk Research, 13 (2010) 861-875.

1298 [81] J. Douglas, Comment on the paper 'A risk-mitigation approach to the management of 1299 induced seismicity' by J. J. Bommer, H. Crowley and R. Pinho, J Seismol, 20 (2016) 393-394.

1300 [82] J.J. Bommer, S. Oates, J.M. Cepeda, C. Lindholm, J. Bird, R. Torres, G. Marroquín, J. 1301 Rivas, Control of hazard due to seismicity induced by a hot fractured rock geothermal 1302 project, Engineering Geology, 83 (2006) 287-306.

1303 [83] M.O. Häring, U. Schanz, F. Ladner, B.C. Dyer, Characterisation of the Basel 1 enhanced 1304 geothermal system, Geothermics, 37 (2008) 469-495.

1305 [84] J. Douglas, H. Aochi, Using Estimated Risk to Develop Stimulation Strategies for 1306 Enhanced Geothermal Systems, Pure Appl. Geophys., 171 (2014) 1847-1858.

1307 [85] M.G. Morgan, Use (and abuse) of expert elicitation in support of decision making for 1308 public policy, Proceedings of the National Academy of Sciences, 111 (2014) 7176-7184.

1309 [86] U.S. Environmental Protection Agency, Expert Elicitation Task Force. White Paper., in, 1310 Washington D.C., 2011.

1311 [87] K.L. Henwood, N.F. Pidgeon, Qualitative research and psychological theorizing, British 1312 Journal of Psychology, 83 (1992) 97-111.

1313 